\title{
Coordinated Control Using Backstepping of DFIG-Based Wind Turbine for Frequency Regulation in High Wind Energy Penetrated System
}

\author{
Mohamed Nadour $\mathbb{D}^{1},{ }^{1}$ Ahmed Essadki, ${ }^{1}$ and Tamou Nasser ${ }^{2}$ \\ ${ }^{1}$ Research Center of Engineering and Health Sciences and Technologies, High Normal School of Technical Education, \\ Mohammed V University, Rabat, Morocco \\ ${ }^{2}$ Research Center of Engineering and Health Sciences and Technologies, \\ Higher National School of Computer Science and Systems Analysis, Mohammed V University, Rabat, Morocco
}

Correspondence should be addressed to Mohamed Nadour; mohamed.nadour@um5s.net.ma

Received 9 September 2019; Revised 21 February 2020; Accepted 9 March 2020; Published 29 April 2020

Academic Editor: Francesco Ripamonti

Copyright (c) 2020 Mohamed Nadour et al. This is an open access article distributed under the Creative Commons Attribution License, which permits unrestricted use, distribution, and reproduction in any medium, provided the original work is properly cited.

\begin{abstract}
The expansion of renewable generation has raised some red flags in terms of power system stability, control, and management. For instance, unlike traditional synchronous energy sources, the doubly-fed induction generator- (DFIG-) based wind turbines (WTs) do not instinctively act against frequency deviations. In fact, the power electronics interfacing the generator, merely controlled to warrant maximum wind power conversion, make its output power and mechanical speed immune to the characteristics of the electric network frequency. Moreover, significant wind power penetration (WPP) promotes the retirement of many traditional generation groups, consequently curtailing the power system corresponding inertia and displacing the primary reserves that are essential to retain the frequency within an acceptable range of variation. This paper explores different control approaches, using backstepping, allowing DFIG-based WTs to engage actively in frequency regulation using a coordinated control of the rotor speed and pitch angle to regulate the system during both partial- and full-load operation modes. The first method momentarily discharges part of the kinetic energy stored in the WT spinning masses, and the second method follows a deloaded operation characteristic, so as to keep a specific power reserve that can be automatically activated at the events of frequency excursions. A study case considering an isolated power system that consists of synchronous generators, DFIG-based wind farm, static load, and a sudden frequency disturbance was performed. The simulation result in a Matlab/Simulink environment highlights the robustness and capability of the coordinated control scheme to furnish, under variant operation conditions, active power aid, consequently lifting the frequency nadir up to a superior level than that obtained with $0 \%$ wind power penetration in the system.
\end{abstract}

\section{Introduction}

The progression from conventional generation groups to nonconventional cleaner energy sources has pressured the power system to encounter significant changes in terms of its structure, operation, control, and management [1-3]. That is to say, as these renewables continue prospering worldwide, the power network will unavoidably confront multiple stability concerns. For instance, at the occurrence of frequency disruption, which reflects a power imbalance between demand and supply, in contrary to synchronous generation sources (reheat steam turbines, nonreheat steam turbines, hydraulics, etc.), where a natural short-term inertial response represented by an instantaneous absorption or release of the kinetic energy stored in the turbines spinning masses and primary reserve activation both serve the power system in restoring and maintaining the electric network frequency within a tolerable spectrum of variation, the doubly-fed induction generator- (DFIG-) based wind turbine (WT), which is the most prominent structure among the wind energy generation technologies [4], does not acquire this inherited characteristic $[5,6]$. As a matter of fact, 
the power electronics interfacing the DFIG to the electrical network are merely controlled to ensure maximum power point tracking (MPPT) and therefore almost entirely dissociate its output power and mechanical speed from the electric network frequency characteristics.

Furthermore, considerable wind power penetration (WPP) promotes the retirement and displacement of many conventional generation groups. Leading to the reduction of the power system's corresponding inertia, hence lower inertial responses supporting the system (the situation is worse especially in isolated systems since their equivalent inertia is already limited), plus, the curtailment of primary reserves typically needed to compensate for power imbalances between the consumption and the production in order to secure the permanent stability of the power system. Therefore, some transmission system operators (TSOs) and grid planners have early revised their grid code specifications in order to securely fit in the wind power generation in their power system [2,7]. Among which, for instance, the European Network of Transmission System Operator for Electricity (ENTSO-E) [8] expects that each of the transmission system operators (TSOs) shall obligate their gridconnected WTs to provide extra active power support comparable to that of conventional generation units to assist in the recovery process using the so-called "frequencysensitive" control methods [9].

The industrial and academic proposed solutions that allow variable speed WTs to engage in frequency regulation can be categorized into two main classes. The first class makes use of the naturally inaccessible WT kinetic energy through some appropriate rotor speed control designs. This class mainly contains two methods including, first, an "artificial" inertial reaction, using the kinetic energy stored in WTs spinning masses, retrieved based on the frequency deviation to counteract frequency disruptions for short-term duration $[1,8,10]$. A study by authors in $[6,11]$ shows that variable speed WT grants more access to the kinetic energy compared to a traditional synchronous generator with equivalent inertia constant, being that the wider the range of speed variation generators can tolerate, the more the kinetic energy can be extracted. However, this method cannot be used alone since it provides assistance only during the transient and has no reaction for quasi-steady state [1]. Then, there is the long-term frequency support where the proposed control strategy expects the WT to shift from MPPT to suboptimal operation mode and a droop controller is used to adapt the WT active power output as a proportion of the frequency deviation [12]. The second class uses the blade pitching to create the power reserve but only when the active power output is higher than the nominal value (full-load operation mode) [13-15].

This subject is recognized and fairly discussed over the past years. However, some concerns still require further analysis. For instance, plenty of published papers such as $[11,13,16,17]$ have only considered the full-load operation of WT, whereas this mode represents only a small scale of WT operation time. As an example, the production of Portuguese grid-connected WTs is beyond the half of its nominal power only during $10 \%$ of the global operation time
[9]. Moreover, few have been the works that have suggested a mix between rotor speed control through power electronics and pitch control for frequency regulation purposes. The authors in [16] have examined a coordinated control scheme, which only incorporates only the short-term inertial response and pitch control comparing the results with existing rotor speed controllers.

This paper explores different control approaches used to enhance WT capability to engage in frequency regulation. First rotor speed control methods, namely, the artificial inertial and the primary frequency regulation responses, are developed. The control is done through the DFIG side converter (DSC) using nonlinear backstepping methodology. Then, an innovative pitch angle control method, utilized to protect the WT against overspeeding and to maintain the power reserve even during a full-load operation mode, is presented.

A study case considering an isolated power system that contains synchronous generators, DFIG-based wind farm, and static loads was examined to compare the capability of each control scheme individually, in terms of furnishing extra active power assistance at the event of a sudden frequency disruption. Then, the simulation results show that a combination of the three control approaches enhances the performance of the DFIG-based wind farm by bringing the frequency nadir up to a higher level than that where the WPP is of $0 \%$ in the power system.

\section{Modelling and Control of DFIG-Based WT}

This section presents some preliminary knowledge, including a brief description of WT and DFIG modelling and control using backstepping. As we shall see in the Results section, compared to the classical control schemes, this control strategy enhances the system stability and robustness especially when parametric variations are registered, which is often the case due to some physical phenomena or modelling uncertainties related to the accuracy of the measuring devices and identification methodologies $[4,18]$.

2.1. Wind Turbine Model. The aerodynamic power $P_{T}$ captured from the wind power $P_{\mathrm{w}}$ is expressed as follows:

$$
P_{T}=P_{w} \cdot C_{p}(\lambda, \beta)=\frac{\rho \pi R^{2} v_{w}^{3}}{2} C_{p}(\lambda, \beta),
$$

where $R$ is the blade radius, $\rho$ is the air density, $v_{w}$ is the wind speed, $\lambda$ is the tip speed ratio, $\beta$ is the blade angles, and $C_{p}$ is the aerodynamic efficiency or the power coefficient approached by the expression given in Appendix [18]. With $\Omega_{T}$ being the WT rotor speed, we have

$$
\lambda=R \cdot \frac{\Omega_{T}}{v_{w}} .
$$

The gearbox that adapts the mechanical speed $\Omega_{m}$ of the DFIG to the rotor speed $\Omega_{T}$ of the WT is modelled, neglecting the mechanical energy losses, by a simple gain $G_{T}$, such that 


$$
\begin{gathered}
\Omega_{m}=G_{T} \cdot \Omega_{T}, \\
T_{T}=G_{T} \cdot T_{g},
\end{gathered}
$$

where $T_{T}$ and $T_{g}$ are the torques at the gearbox input and output, respectively. Then, with $T_{\mathrm{em}}$ being the electromagnetic torque of the generator, $J_{\mathrm{wt}}$, the system (WT and DFIG) total inertia, and $f$ the friction, according to the fundamental equation of dynamic, we can write

$$
J_{w t} \frac{d \Omega_{m}}{d t}=T_{g}-T_{e m}-f \cdot \Omega_{m}
$$

2.2. DFIG Modelling and Control. In this work, we have adopted the field-oriented control, joining the stator flux to the $d$-axis of the Park reference frame ( $\psi \mathrm{sq}=0$ and $\psi \mathrm{sd}=\psi \mathrm{s})$, in order to dissociate the control of active power $P_{s}$ and reactive power $Q_{s}$. Neglecting the stator resistance $R_{s}$, which is a realistic approximation for high-power generators [4], the state model of the DFIG can be determined by the following equation [19]:

$$
\begin{aligned}
& \left\{\begin{array}{l}
\dot{P}_{s}=\mu\left(V_{r q}+R_{r} I_{r q}+\chi I_{r d}-\eta\right), \\
\dot{I}_{r q}=-\sigma\left(V_{r q}+R_{r} I_{r q}+\chi I_{r d}-\eta\right), \\
z_{1}=P_{s},
\end{array}\right. \\
& \left\{\begin{array}{l}
\dot{Q}_{s}=\mu\left(V_{r d}+R_{r} I_{r d}-\chi I_{r q}\right), \\
\dot{I}_{r d}=-\sigma\left(V_{r q}+R_{r} I_{r d}-\chi I q\right), \\
z_{2}=Q_{s},
\end{array}\right.
\end{aligned}
$$

with $\quad \alpha=\left(1-\left(M^{2} / L_{r} L_{s}\right)\right) ; \mu=\left(V_{s} M / \alpha L_{r} L_{s}\right) ; \chi=g \omega_{s} \alpha L_{r}$; $\eta=g\left(M V_{s} / L_{s}\right) ; \sigma=\left(1 / \alpha L_{r}\right)$.

The subscripts $d$ and $q$ denote the two axes of the Park rotating reference frame, and $v_{r}, v_{s}, i_{r}$, and $i_{s}$ are being, respectively, the rotor and the stator voltages $(\mathrm{V})$ and currents $(\mathrm{A}) . \omega_{s}$ and $\omega_{r}$ are the angular speeds of the rotating stator and the rotor electromagnetic fields ( $\mathrm{rad} / \mathrm{s}) . M, L_{r}$, and $L_{s}$ are the mutual, rotor, and stator inductances $(\mathrm{H})$, and $R_{r}$ is the rotor resistance.

Moreover, with $p$ being the pair of poles, the electromagnetic torque can be determined by the following equation:

$$
T_{e m}=p \frac{M}{L_{s}} \Psi_{s d} i_{r q} .
$$

The benefit of the backstepping control approach relies on its ability to dissociate complex nonlinear systems into multiple simplified design problems (called steps or subsystems) using the so-called virtual control variables (VCVs). In each step, we virtually deal with a simple singleinput and single-output subsystem, and each step provides virtual reference for the following one using Lyapunov's functions to guarantee the stability of the subsystem. In the last step, the actual control variable (ACV) that insures the stability of the overall system can be finally determined [19].

The DFIG side converter (DSC) in Figure 1 is controlled to regulate the stator active power $P_{s}$ and the stator reactive power $Q_{s}$ to their references $P_{s r}$ and $Q_{s r}$, respectively. From equation (4), we have two second-order systems; therefore, the backstepping control design for each is divided into two subsystems as shown in Figure 2.

2.3. Subsystem A (Current Reference VCV). First, we select Lyapunov's quadratic functions $V_{1}$ and $V_{2}$, and then, we define the error variables such that

$$
\left\{\begin{array} { l } 
{ V _ { 1 } = \frac { 1 } { 2 } e _ { 1 } ^ { 2 } , } \\
{ V _ { 2 } = \frac { 1 } { 2 } e _ { 2 } ^ { 2 } , }
\end{array} \left\{\begin{array}{l}
e_{1}=P_{s}^{*}-P_{s} \longrightarrow \dot{e}_{1}=\dot{P}_{s}^{*}-\dot{P}_{s} \\
e_{2}=Q_{s}^{*}-Q_{s} \longrightarrow \dot{e}_{2}=\dot{Q}_{s}^{*}-\dot{Q}_{s} .
\end{array}\right.\right.
$$

According to backstepping theory, in order to ensure a stable tracking behavior, the derivative of prechosen Lyapunov's functions must be strictly negative, such that

$$
\left\{\begin{array}{l}
\dot{V}_{1}=e_{1} \cdot \dot{e}_{1}=-h_{1} e_{1}^{2}, \\
\dot{V}_{2}=e_{2} \cdot \dot{e}_{1}=-h_{2} e_{2}^{2},
\end{array}\right.
$$

with $h_{1}$ and $h_{2}$ being the positive backstepping tuning coefficients. The current reference VCVs can then be mathematically obtained using equations (5), (7), and (8) such that

$$
\left\{\begin{array}{l}
\dot{I}_{r q}^{*}=\frac{1}{\mu R_{r}}\left(\dot{P}_{s}^{*}+h_{1} e_{1}\right)-\frac{1}{R_{r}}\left(V_{r q}+\chi I_{r d}-\eta\right), \\
\dot{I}_{r d}^{*}=\frac{1}{\mu R_{r}}\left(\dot{Q}_{s}^{*}+h_{2} e_{2}\right)-\frac{1}{R_{r}}\left(V_{r d}-\chi I_{r d}\right) .
\end{array}\right.
$$

2.4. Subsystem B (Voltage Reference $A C V$ ). Note that the $\operatorname{VCVs}\left(I_{r d}^{*}\right.$ and $\left.I_{r q}^{*}\right)$ from the previous step (equation (9)) are the desired variables for this step. Therefore, we select Lyapunov's functions $V_{3}$ and $V_{4}$ and define the error variables:

$$
\left\{\begin{array} { l } 
{ V _ { 3 } = \frac { 1 } { 2 } ( e _ { 1 } ^ { 2 } + e _ { 3 } ^ { 2 } ) , } \\
{ V _ { 4 } = \frac { 1 } { 2 } ( e _ { 2 } ^ { 2 } + e _ { 4 } ^ { 2 } ) , }
\end{array} \left\{\begin{array}{l}
e_{3}=I_{r d}^{*}-I_{r q} \longrightarrow \dot{e}_{3}=\dot{I}_{r q}^{*}-\dot{I}_{r q}, \\
e_{4}=I_{r d}^{*}-I_{r d} \longrightarrow \dot{e}_{4}=\dot{I}_{r d}^{*}-\dot{I}_{r d} .
\end{array}\right.\right.
$$

Similarly, in order to secure a stable tracking behavior, according to the backstepping theory, the derivative of Lyapunov's functions must be strictly negative such that

$$
\left\{\begin{array}{l}
\dot{V}_{3}=\left(e_{1} \cdot \dot{e}_{1}\right)\left(e_{3} \cdot \dot{e}_{3}\right)=-h_{1} e_{1}^{2}-h_{3} e_{3}^{2}, \\
\dot{V}_{4}=\left(e_{2} \cdot \dot{e}_{2}\right)\left(e_{4} \cdot \dot{e}_{4}\right)=-h_{2} e_{2}^{2}-h_{4} e_{4}^{2} .
\end{array}\right.
$$

Using the same steps, the voltage reference ACV can be mathematically determined using equations (5), (10), and (11):

$$
\left\{\begin{array}{l}
V_{r q}^{*}=\left\{-h_{3} e_{3}-\dot{I}_{r q}^{*}-\mu e_{1}\right\} \frac{1}{\sigma}-\left\{R_{r} I_{r q}+\chi I_{r d}+\eta\right\}, \\
V_{r d}^{*}=\left\{-h_{4} e_{4}-\dot{I}_{r d}^{*}-\mu e_{2}\right\} \frac{1}{\sigma}-\left\{R_{r} I_{r d}-\phi I_{r d}\right\},
\end{array}\right.
$$




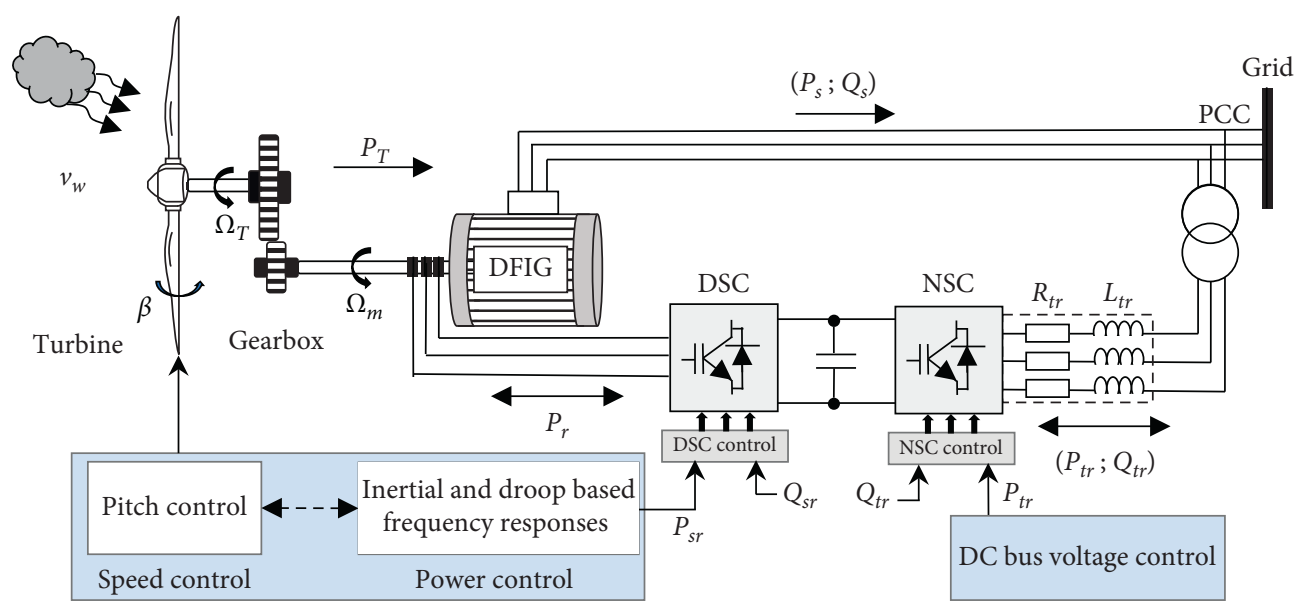

Figure 1: The complete structure of frequency-sensitive DFIG-based WT control.

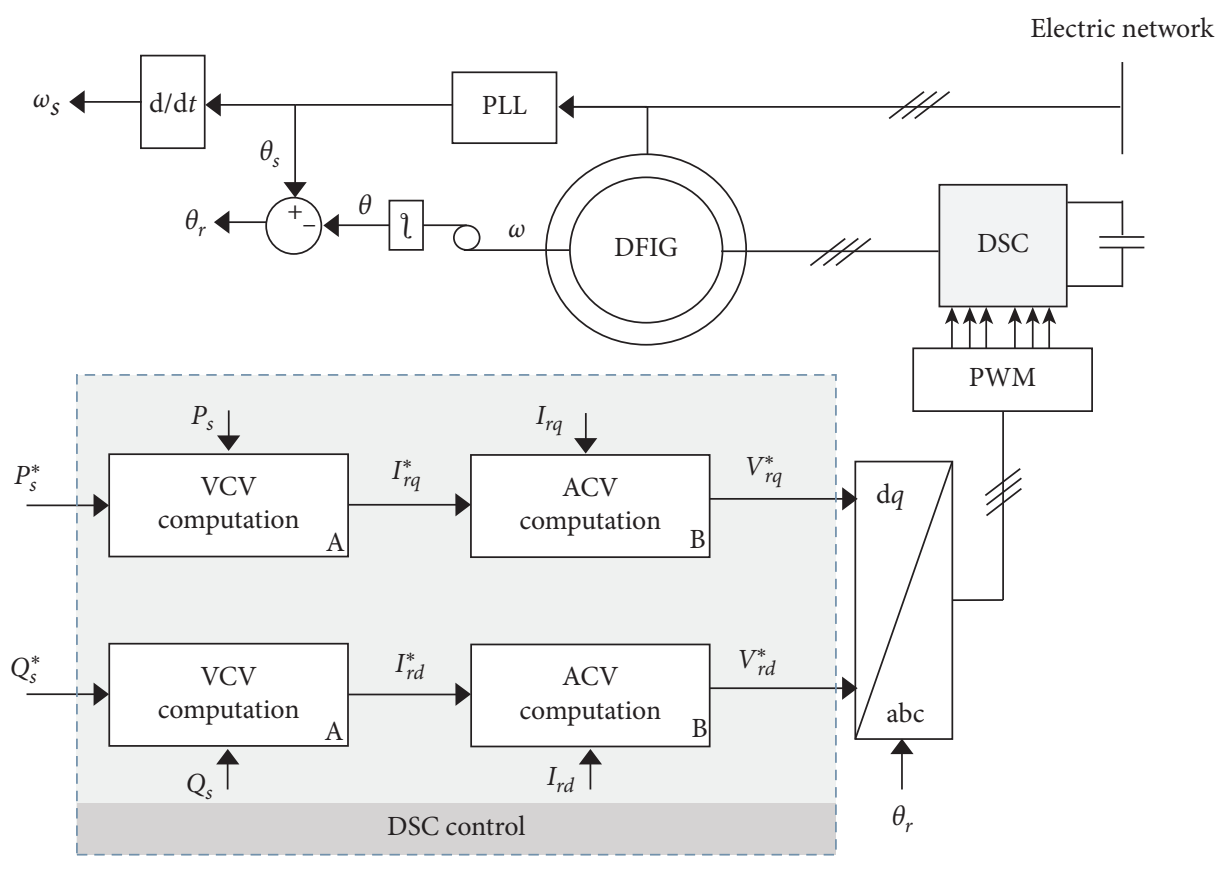

FIGURE 2: DSC backstepping control.

with $h_{1}, h_{2}, h_{3}$, and $h_{4}$ being some strictly positive constants called the backstepping setting coefficients, used on the one hand to guarantee the stability of the system and on the other hand to ensure a quick dynamic response of the group controller system.

\section{3. "Electric Network Frequency- Sensitive" Control}

Figure 1 illustrates the complete DFIG-based WT structure including the network side converter (NSC) used to regulate the DC link voltage $V_{d c}$ and the reactive power exchanged through the filter $Q_{t r}$. The DFIG side converter (DSC) used to regulate the stator reactive power $Q_{s}$ to zero in order to get a unity power factor at the point of common coupling (PCC), until the electric network operator demands otherwise, and to adjust almost instantaneously, the stator active power $P_{s}$ according to the electric network frequencysensitive control loops. Finally, the pitch angle controller adapts the mechanical power to maintain the frequency regulation capability even under the full-load operation condition. Each controller will be analysed thoroughly in the next subsections.

3.1. Artificial Inertial Response. The inertial response permits the DFIG to reproduce synchronous generators behaviour, providing an active power support for the power system during the transient. It consists in customizing the electromagnetic torque reference $T_{\mathrm{emr}}$, hence the active power reference $P_{s r}$, as a proportion of the rate of change of the frequency (ROCOF). At the event of frequency disruption, the electromagnetic torque set point rises by $\Delta T_{\text {em-IN }}$ causing a deceleration of the WT rotor speed $\Omega_{m}$ and, as a 


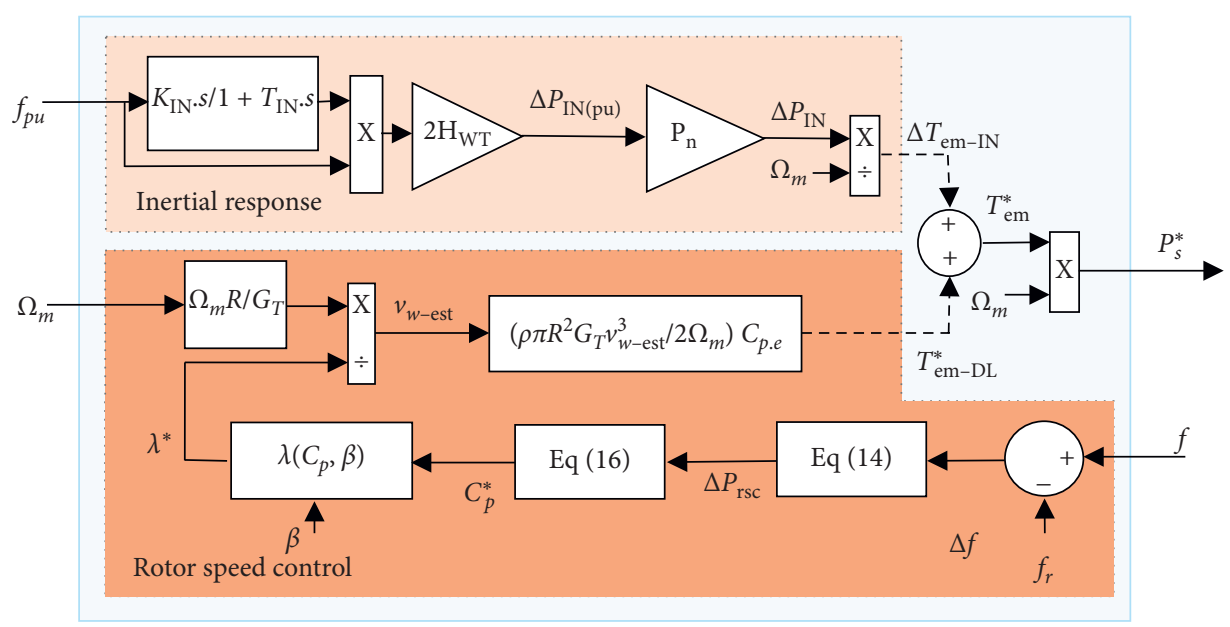

FIgURE 3: Coordinated frequency-sensitive control scheme.

consequence, discharging a portion of the kinetic energy stored in the WT spinning masses. The mechanism is chosen to be proportionate to that of synchronous generators, and thus, the additional power injected to the network can be expressed as follows:

$$
\Delta P_{\mathrm{IN}(\mathrm{pu})}=2 H_{T} \cdot f_{\mathrm{pu}} \frac{\mathrm{d} f_{\mathrm{pu}}}{\mathrm{d} t},
$$

where $f_{\mathrm{pu}}$ is the per-unit system frequency and $H_{T}$ the total inertia constant (DFIG and WT) given by [5]

$$
H_{T}=H_{\mathrm{DFIG}}+H_{\mathrm{WT}}=H_{\mathrm{DFIG}}+\frac{1}{2} \frac{J_{T} \Omega_{\mathrm{rated}}^{2}}{S_{\text {rated }}} .
$$

$S_{\text {rated }}$ and $\Omega_{\text {rated }}$ are, respectively, the rated power and rated mechanical speed. The equation that relates the electromagnetic torque to the frequency can be determined from equation (13) by the following expression:

$$
\Delta T_{\mathrm{em}-\mathrm{IN}(\mathrm{pu})}=2 H_{T} \cdot f_{\mathrm{pu}} \frac{\mathrm{d} f_{\mathrm{pu}}}{\mathrm{d} t} \frac{1}{\Omega_{m(\mathrm{pu})}} .
$$

Furthermore, since the frequency is estimated by means of a phase-locked loop (PLL), a low-pass filter needs to be introduced into the control scheme in order to reduce the impact of the small noises as shown in Figure 3, where $T_{\mathrm{IN}}$ represents the time constant of the filter and $K_{\mathrm{IN}}$ its gain that determines the amount of additional injected wind power in case of a frequency excursion.

3.2. Speed Droop Control. The artificial inertial response can only be utilized to assist the system during the transitory phase known as "dynamic frequency variation" [20]. However, in order to enable the WT to provide active power support for an extended period of time, another electric network frequency-sensitive control loop that takes under consideration the quasi-steady-state frequency deviation should be added as shown in Figure 3. The latter obligates the WT to operate following a "deloaded operation characteristic (DL)," as illustrated in Figure 4, creating a specific power reserve that can be automatically activated to support the power system when active power is needed at the event of

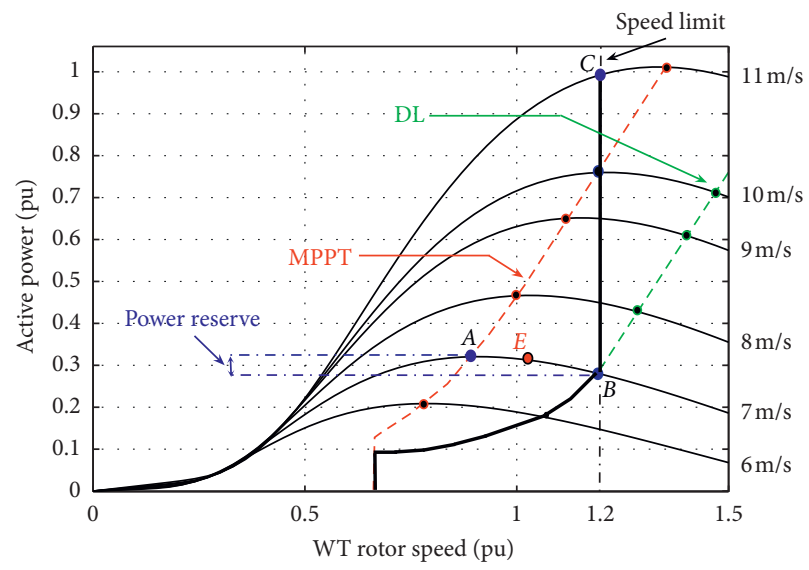

FIgURE 4: Deloaded operation.

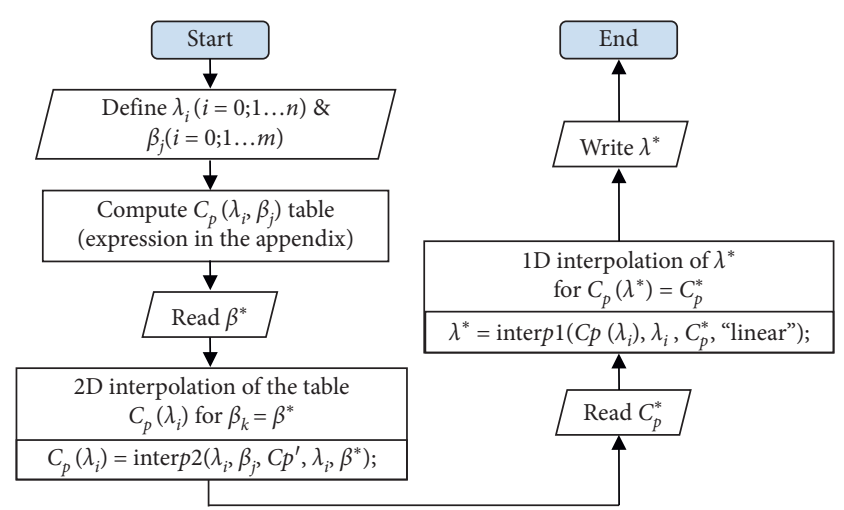

Figure 5: Organigram for the tip speed ratio reference computation.

frequency disruption. The creation of the power reserve is done through the acceleration of mechanical speed $\Omega_{m}$, by acting on the electromagnetic torque reference $T_{\mathrm{emr}-\mathrm{DL}}^{*}$, hence the active power reference $P_{s}^{*}$, moving the operation point from $A$ (which corresponds to the maximum power point tracking (MPPT) operation) to $B$ (which corresponds 
to the deloaded power point tracking (DL) operation) as shown in Figure 3, such that

$$
\left\{\begin{array}{l}
P_{B}=\left(1-R_{f}\right) P_{A}, \\
\Omega_{B}>\Omega_{A}=\Omega_{\mathrm{mppt}}
\end{array}\right.
$$

where $R_{f}$ is the reserve factor and $P_{A}$ and $\Omega_{A}$ are being, respectively, the active power and the mechanical speed of MPPT operation, given by

$$
\left\{\begin{array}{l}
P_{A}=\left[\frac{\rho \pi R^{2} G_{T}}{2 \Omega_{m}} v_{\mathrm{w}-\mathrm{est}}^{3} C_{\mathrm{pmax}}\right] \Omega_{m} \longrightarrow \mathrm{MPPT}, \\
v_{\mathrm{w}-\mathrm{est}}=\frac{R \Omega_{m}}{G_{T} \lambda_{\mathrm{mppt}}} ; \\
\lambda_{\mathrm{mppt}}: \text { optimal tip speed ratio. }
\end{array}\right.
$$

Theoretically speaking, the creation of the reserve can also be achieved by decelerating the mechanical speed. However, it is preferred to use the acceleration method to preserve and even increase the amount of kinetic energy stored in the WT. At the event of frequency drop, the controller changes the electromagnetic torque reference, decelerating the WT (moving from the point $B$ through the point $E$ to the maximum point $A$ ) as shown in Figure 4, consequently rising the wind power production by a specific quantity $\Delta P_{\text {rsc }}$ chosen to be proportionate to the frequency deviation, such that

$$
\left\{\begin{array}{l}
\Delta P_{\mathrm{rsc}}=K \cdot\left(f-f_{r}\right)=K \cdot \Delta f \\
\Delta P_{\mathrm{rsc}-\max }=R_{f} * P_{A} \longrightarrow \text { total power reserve, }
\end{array}\right.
$$

with $f$ and $f_{r}$ being, respectively, the measured and nominal frequency $50 \mathrm{~Hz}$ and $K$ is an energy factor determined as a function of the droop parameter $\delta$ :

$$
K=\left(\frac{P_{\text {rated }}}{\delta f_{r}}\right)
$$

with $P_{\text {rated }}$ being the generator's rated power.

The creation and activation (as function of $\Delta P_{\text {rsc }}$ ) of the power reserve are achieved through modifying the power coefficient reference $C_{p}{ }^{*}$ and the tip speed ratio reference $\lambda^{*}$ in equation (17). Therefore, the power coefficient new reference $C_{p}{ }^{*}$ can be determined from equation (1) by the following expression:

$$
\left\{\begin{array}{l}
C_{p}^{*}\left(\lambda^{*}, \beta\right)=\left(1-R_{f}\right) C_{\mathrm{pmax}} * \frac{\Delta P_{\mathrm{rsc}}}{0.5 \rho \pi R^{2} v_{w}^{3}}, \\
C_{p}^{*}\left(\lambda^{*}, \beta\right)=\left(1-R_{f}\right) C_{\mathrm{pmax}} \text { if } \Delta P_{\mathrm{rsc}}=0 .
\end{array}\right.
$$

${ }^{*}, p^{*}, p$. While the reference of the tip speed ratio $\lambda^{*}$, which depends on the power coefficient reference $C \mathrm{p}^{*}$ and fhe angle of orientation of the blades $\beta$, can be determined using linear interpolation adopting the algorithm presented in Figure 5.

The block diagram of rotor speed control is illustrated in Figure 3.
Finally, the rotor speed controller along with the inertial response $\Delta P_{\mathrm{IN}}$ sets the active power reference $P_{\mathrm{sr}}$ for the DSC control according to the following expressions:

$$
\left\{\begin{array}{l}
P_{s}^{*}=T_{\mathrm{em}}^{*} \cdot \Omega_{m} \\
T_{\mathrm{em}}^{*}=T_{\mathrm{em}-\mathrm{DL}}^{*}+\Delta T_{\mathrm{em}-\mathrm{IN}} .
\end{array}\right.
$$

3.3. Pitch Control. The contribution of a WT to the global power reserve can be achieved either by accelerating the rotor speed or by the orientation of the pitch angle. During partial-load operation mode (wind speed below rated), the first method could be used alone in case of a tolerable power reserve. However, it becomes incapable if a larger reserve is requested, since the rotor speed should not exceed its maximum value (point $B$ in Figure 4 ). In that case, the second method is then called to take over. The pitch controller calculates the appropriate pitch angle $\beta_{\text {ref }}$ that prevents the generator speed from surpassing the maximum value $1.2 \mathrm{pu}$, and $\beta_{\text {ref }}$ is then transferred to the pitch system, which will either direct the fluid to the cylinders or the power to the motors, depending on the actuator, to increase the angle of the blades, consequently adjusting their lift for further mechanical power curtailment.

For high wind speeds, the WT is at full-load operation mode, and the pitch system is already activated to keep the rotor speed at its maximum value (point $C$ in Figure 4). Note that, contrary to the classical WT control, the regulation using pitch angle control could be activated for all wind conditions. The dynamic of the pitch actuator can be modelled using the following transfer function, with $T_{p}$ being the time constant of the pitch system [21]:

$$
\beta=\frac{1}{1+T_{p} s} \beta_{\text {ref }} \text {. }
$$

As previously mentioned, the pitch angle $\beta$ is used to regulate the rotor speed $\Omega_{m}$. The process is highly nonlinear, and there is no direct relationship between these two variables. Traditionally, a gain scheduling control method is implemented to make up for the existent nonlinear aerodynamic behaviour [21]. However, the deloaded operation of the WT, used for frequency regulation purposes, complicates the control since the adjustment of the process gain now depends on not only the wind speed but also the power set point [21]. Accordingly, a simpler and more efficient approach is presented in this paper. It is based on $C_{p}(\lambda, \beta)$ table inversion since the nonlinear characteristic is essentially brought by its curve. The architecture of the control approach is depicted in Figure 6.

The reference of the pitch angle $\beta_{\text {ref }}$ is determined using the reference of the power coefficient $C_{p}^{*}$, an estimation of tip speed ratio $\lambda^{*}$, and an inversion of the $C_{p}(\lambda, \beta)$ table. Moreover, $\lambda^{*}$ is determined using the rotor speed measurement and $C_{p}^{*}$ is obtained from the aerodynamic torque reference $T_{T}^{*}$, after inverting each element of the WT model (equation (1) to equation (4)) (note that in the steady state, $T_{\mathrm{em}}=T_{g}$ ). As a consequence, the process view by the controller becomes linear, and electromagnetic torque reference 


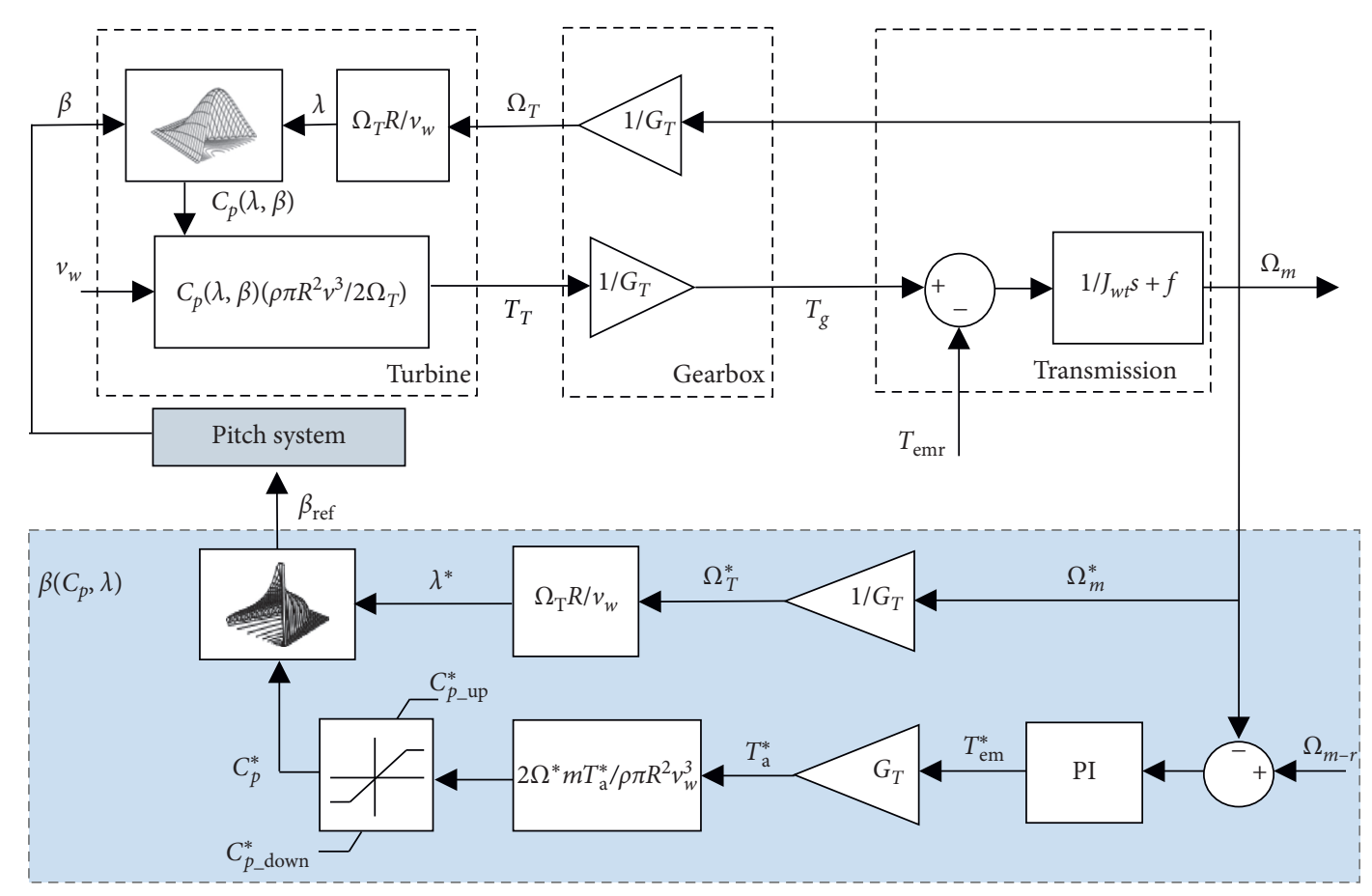

FIGURE 6: Block diagram of the rotor speed control.

$T_{\mathrm{em}}^{*}$ could be provided using a simple constant gain PI controller. A dynamic saturation is used to limit $C_{p}^{*}$ reference to $C_{p \text {-up }}^{*}\left(\lambda, \beta=30^{\circ}\right)$ and $C_{p \text {-down }}^{*}\left(\lambda, \beta=0,1^{\circ}\right)$.

The inversion of the $C_{p}(\lambda, \beta)$ table could be applied to any mathematical approximation. It is based on 1- and 2dimensional linear interpolations, and it can be depicted in the organigram (Figure 7)

\section{Results and Discussions}

4.1. General Discussion. The power system is exposed to many forms of disturbances. A load change results in variation of the electrical torque $T_{e}$ output of all generators, and a change in the production results in variation of the mechanical torque $T_{m}$ of all generators. The frequency deviations reflect the mismatches between the electrical $T_{e}$ and mechanical $T_{m}$ torques, as represented by the following equation of motion [22]:

$$
T_{m}-T_{e}=2 H \frac{\mathrm{d} \omega}{\mathrm{d} t}=2 H \frac{\mathrm{d} f}{\mathrm{~d} t},
$$

where $H$ is the power system's corresponding inertia constant and $\omega$ and $f$ are the (per unit) rotational speed and the ENF, respectively [23]. Equation (20) can be expressed in terms of the electrical $P_{e}$ and mechanical $P_{m}$ powers, such that

$$
\begin{aligned}
& \left(P_{m 1}-P_{e 1}\right)+\left(\Delta P_{m}-\Delta P_{e}\right)=\left(\omega_{1}-\Delta \omega\right)\left[\left(T_{m 1}-T_{e 1}\right)\right. \\
& \left.\quad+\left(\Delta T_{m}-\Delta T_{e}\right)\right]
\end{aligned}
$$

where we denote the deviations by the prefix $(\Delta)$ and the steady-state values by the subscript (1). with $\omega_{1}(\mathrm{pu})=1$ and by ignoring the higher order terms and adopting the realistic

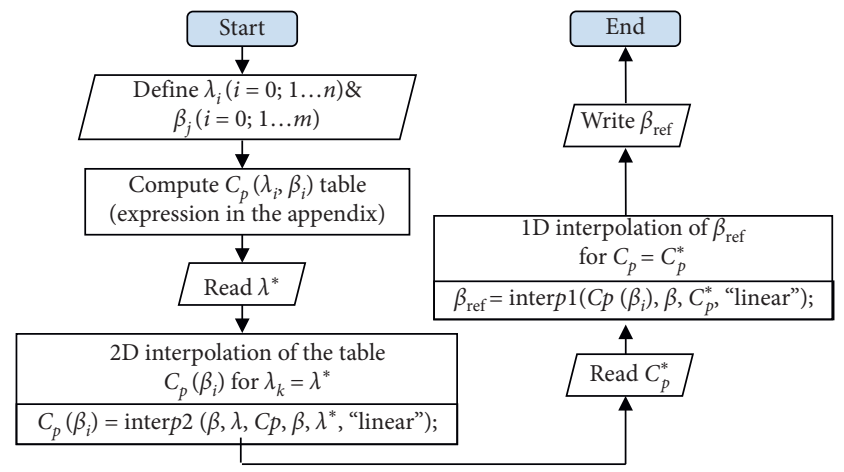

Figure 7: Organigram of the $C_{p}$ table inversion.

assumption of $P_{m 1}=P_{e 1}$ and $T_{m 1}=T_{e 1}$ in the steady state. Equation (24) can further be adjusted into [22]

$$
\left(\Delta P_{m}-\Delta P_{e}\right)=\left(\Delta T_{m}-\Delta T_{e}\right) \text {. }
$$

Replacing into equation (23), we can write

$$
\Delta P_{m}-\Delta P_{e}=2 H \frac{\mathrm{d} \Delta \omega}{\mathrm{d} t}=2 H \frac{\mathrm{d} \Delta f}{\mathrm{~d} t} .
$$

In this work, we have considered the load sensitivity to frequency deviations. Being that practically an abrupt change in frequency will cause a variation of the power demand [22]. The overall network frequency-dependent characteristic of loads can be represented by the following equation:

$$
\Delta P_{e}=\Delta P_{l}+D \Delta f
$$

with $\Delta P_{1}$ being the non-frequency-sensitive load variation and $D \Delta \omega$ is frequency-sensitive load variation. The coefficient $D$ represents the self-regulation of loads, and it is 
expressed as a percent change in load for $1 \%$ deviation in frequency [22]. Substituting into equation (26), we can write

$$
\Delta P_{m}-\Delta P_{l}=2 H \frac{\mathrm{d} \Delta f}{\mathrm{~d} t}+D \Delta f .
$$

4.2. Power System Modelling. To investigate the performances of the proposed control strategies, a model of a small power system, based on the scheme illustrated in Figure 8, was designed in Matlab/Simulink environment. It consists of four identical conventional generating units ( $n=4$ medium power hydroelectric generators) $[2,22]$; each has a power rating of $S_{i}=100 \mathrm{MVA}$, an inertia constant of $H_{i}=5.0 \mathrm{~s}$ on 100 MVA base, and a droop for the speed governor $\delta_{i}=0.2$, feeding a total load of $220 \mathrm{MW}$. For the analysis of frequency regulation capability, we are concerned with the collective behaviour of all generators in the power system. Therefore, in this study, all conventional synchronous generators are represented by a single equivalent machine driven by the mechanical outputs of each turbine [22]. The power rating of the equivalent generator is of $S_{\text {eq }}=\mathrm{n} S_{i}$, and the equivalent droop $\delta_{\text {eq }}$ and the corresponding inertia constant of the power system $H_{\mathrm{eq}}$ can be determined using the following equations:

$$
\begin{gathered}
H_{\text {eq }}=\frac{n H_{i} S_{i}}{S_{\text {eq }}} ; \\
\delta_{\text {eq }}=\frac{\delta_{i}}{n} .
\end{gathered}
$$

Note that the synchronous generators are operating without automatic generation control (AGC), and only primary frequency regulation is considered in this study, which is practically sufficient for the research objectives.

4.3. Artificial Inertial Response Evaluation. In order to examine the implemented artificial inertial control behaviour, we have compared three simulation scenarios as summarized in Table 1.

The first scenario $S 1$ represents the reference case where the first, second, and third synchronous generation units provide both inertial response and primary frequency control (PFC), while the fourth synchronous generation unit is providing only its inherited inertial reaction without primary frequency response (no PFC). Thus, according to equation (29), the system equivalent inertia remains constant $H_{\mathrm{eq}}=5.0 \mathrm{~s}$, but the equivalent droop coefficient is now $\delta_{\text {eq }}=0.066$. The remaining scenarios represent the case where the fourth synchronous generation unit is replaced with a wind farm (WF) with an equivalent power rating, where S2 and S3 are, respectively, the wind farm cases without and with inertial control implemented. In this case, the wind power penetration rises up to $L_{P}=25 \%$; therefore, the equivalent inertia constant is decreased to $\mathrm{H}_{\mathrm{eq}}^{\prime}=\mathrm{H}_{\mathrm{eq}}$ $\left(1-L_{p}\right)=3.75$, while the equivalent droop remains constant $\delta_{\text {eq }}^{\prime}=0.066$. A sudden rise in load by $20 \mathrm{MW}$ (0.05 pu system base) is introduced to the system at $t=300 \mathrm{~s}$.

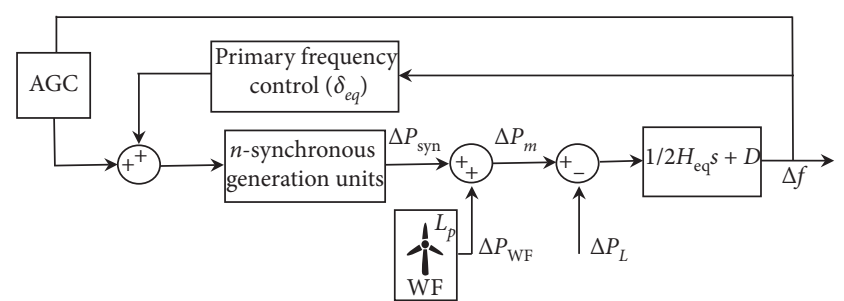

FIGURE 8: Electric network frequency regulation control scheme of a power system.

TABLE 1: Simulation scenarios.

\begin{tabular}{lccc}
\hline Scenarios & S1 & S2 & S3 \\
\hline Generation units 1, 2, and 3 & C & C & C \\
Generation unit 4 & C & NC & NC \\
Wind farm & no PFC & C & C \\
& NC & no IC & only IC
\end{tabular}

C: connected; NC: nonconnected; PFC: primary frequency control; IC: inertial control.

Figure 9 portrays the dynamic reaction of the electric network frequency for the three simulation scenarios. With scenario S1 being the reference case, it can be observed that the deepest frequency nadir, the worst case, is obtained with scenario S2 where the artificial inertial response of WTs is disabled. That is mainly due to the reduction of the system equivalent inertia caused by the increase of the wind power penetration $L_{p}$ to $25 \%$ in the system. Meanwhile, the narrow frequency nadir, the finest case, is obtained with scenario S3 where the inertial response is enabled, and with an appropriate gain $\mathrm{K}_{\mathrm{IN}}$ choice, the inertial support from the WTs could be even greater than that obtained from the synchronous generation unit. Since the wider the range of speed variation, the bigger the amount of kinetic energy can be extracted.

Figures 10-12 show the dynamic behaviour of a single WT for different operation conditions. Initially (before the disturbance), the rotor speed and the active power output are maintained to their optimal values corresponding to MPPT. At the event of frequency drop $t=120 \mathrm{~s}$, and when the wind speed is below rated $v_{w}=6.5 \mathrm{~m} / \mathrm{s}$ (partial-load operation mode), the sequence of events that occur can be summarized as follows:

(i) The controller adjusts the electromagnetic torque reference causing a deceleration of the rotor speed (Figure 10(a)).

(ii) The rotor speed is below its maximum value $(>1.2 \mathrm{pu})$; therefore, the pitch angle is kept at zero (Figure 11(a)).

(iii) The reduction of the rotor speed causes the extraction of a portion of the kinetic energy stored in the spinning masses (Figure 12(a)). This extra active power will be used to support the power system in recovering the frequency to $50 \mathrm{~Hz}$.

(iv) The countering spike of the output power (Figure $12(\mathrm{a})$ ) at roughly $t=310 \mathrm{~s}$ can be explained 


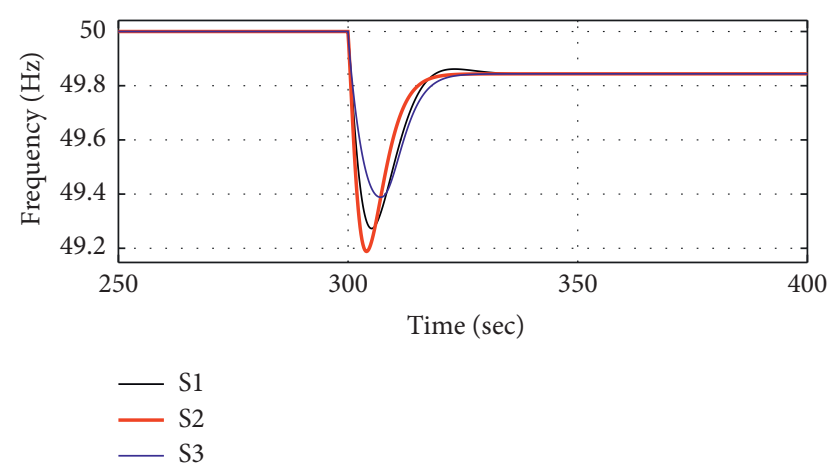

Figure 9: Electric network frequency deviation for different scenarios.

as follows: let us consider that the WT was operating at point $A$ (Figure 4), with the rotor speed reduction, the WT will move to a suboptimal power extraction operation point at the end of the inertial reaction. Therefore, less power will be delivered until full recovery of the WT.

For a high wind speed $v_{w}=15 \mathrm{~m} / \mathrm{s}$ (full-load operation mode), the sequence of events that occur can be summarized as follows:

(i) The pitch controller (Figure 11(b)) maintains the rotor speed at its maximum value $(\approx 1.2 \mathrm{pu})$ (Figure 10(b)).

(ii) The controller tries to adjust rotor speed, but since the pitch controller is activated in this mode, it counteracts the action by reducing the pitch angle, thus indirectly exploiting the mechanical power that was already curtailed by the positive pitch angle to create the power surge (Figure 12(b)). Not that the power response at this mode requires no recovery process since the pitching system is the one responsible for the contribution.

In order to highlight the merits of using a backstepping control algorithm instead of classical controllers, it is particularly important to analyse the system performance under some kind of disturbances. Therefore, since the machine parameters are usually exposed to many forms of inaccuracies especially due to the measuring devices, identification methodology, or several natural phenomena, a robustness test was carried out to compare the performance of the proposed control strategy versus classical PI controllers when parametric variations are registered. The test consists in purposefully modifying the rotor resistance $R_{r}$ of the DFIG by $50 \%$ and the stator inductance $L_{s}$ by $10 \%$ from their normal values.

Figures 12 and 13 show, respectively, the evolution of the DFIG stator active and reactive powers, and Figures 14 and 15 , respectively, show the evolution of $d$ and $q$ components of the rotor currents. The test highlights the high sensitivity of classical PI controllers towards parametric variation, which is notably observed due to the appearance of a significant static error in all simulation results, whereas the proposed backstepping control algorithm demonstrates an exquisite disturbance rejection, being that all the outputs converge correctly to their designated references. Moreover, the three-phased stator current sinusoidal waveform is shown in Figure 16.

4.4. Speed Droop Control Evaluation. The performance of the proposed speed droop control will be evaluated for the following simulation cases.

Case 1: partial-load operation mode (wind speed $v_{w}=6.5 \mathrm{~m} / \mathrm{s}$ )

Case 1: Full-load operation mode (wind speed $\left.v_{w}=15 \mathrm{~m} / \mathrm{s}\right)$

The set of results shown in the following figures demonstrates the capability of the proposed control strategy to respond to a sudden active power call at $t=150 \mathrm{~s}$. Before the arrival of the frequency drop, the WT is running at a rotational speed higher than the optimum $\left(\Omega>\Omega_{\text {mppt }}\right.$ ), in order to lower the aerodynamic conversion efficiency represented by $C_{p}$ and, therefore, to operate following a deloaded operation characteristic with the power reserve being created. For the research objectives, this work presumes that the WT is operating with a reserve factor $R_{f}=10 \%$, while on the practical level the power margins are generally specified by the grid codes.

At the arrival of frequency excursion $(t=150 \mathrm{~s})$, the sequence of events that occur, under partial-load operation mode, can be summarized as follows:

(i) The step in the output power reference (by $\Delta P_{\text {rsc }}$, Figure 3) modifies the electromagnetic torque reference $T_{\mathrm{em}}^{*}$ causing the rotor speed reduction as shown in Figure 17(a)

(ii) The rotor speed is below its maximum value, the pitch control is not required in this case, and therefore, the pitch angle is maintained at zero (Figure 18(a))

(iii) The rotor speed deceleration rises the power coefficient $C_{p}$ to its maximum value (Figure 4 ) as shown in Figure 19(a) allowing, consequently, the WT to activate its full power reserve

(iv) The power reserve activation rises the output power of the WT by $\Delta P_{\text {rsc }}$ (Figure 20(a)), therefore allowing it to participate in the frequency recovery process

(v) The power peaks induced as shown in Figure 20(a) demonstrate the benefit from creating the power reserve by acceleration of the rotor speed, the left side of the power curve Figure 4, since now more kinetic energy is at our disposal, and it can be used whenever the WT is decelerating

(vi) When the frequency recovers at $t=400 \mathrm{~s}$, the control strategy reaccelerates the WT (Figure 17(a)), lowering the power coefficient (Figure 19(a)), in order 


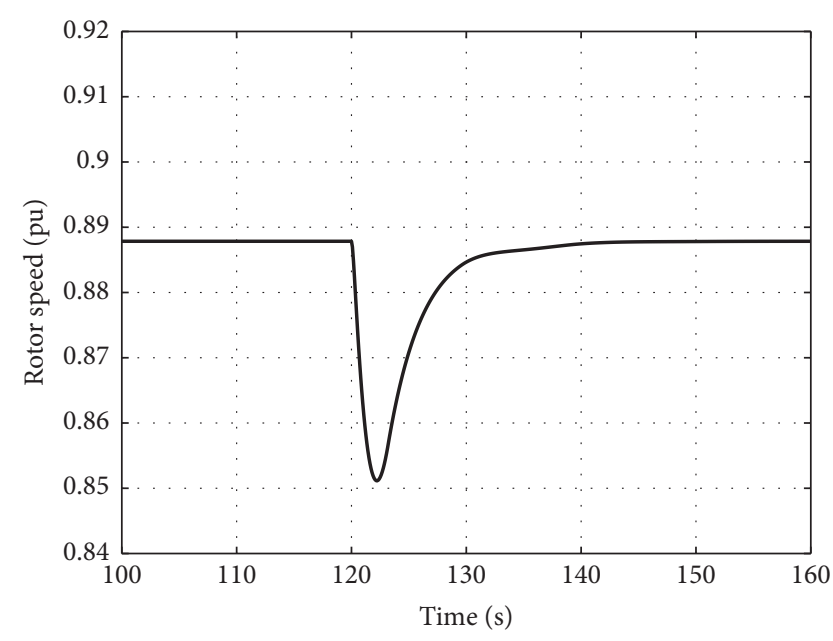

(a)

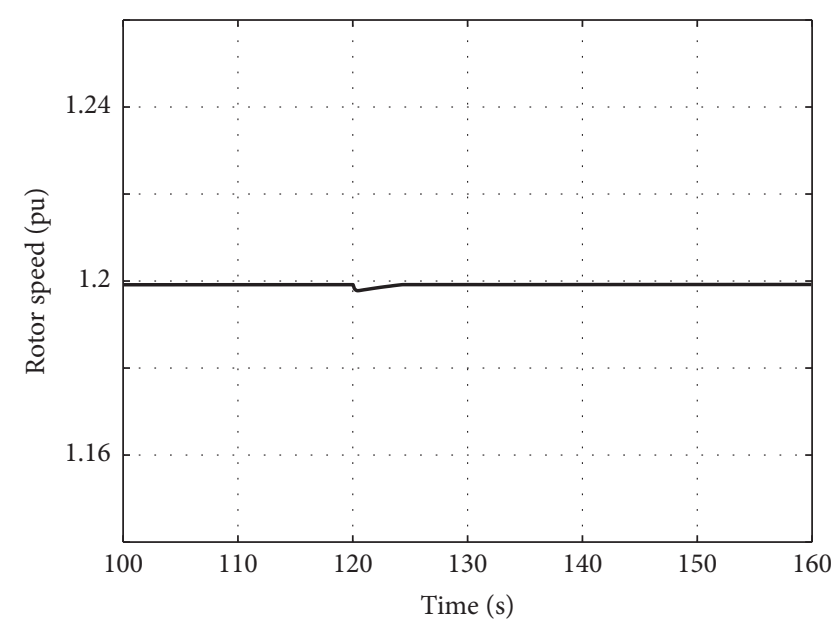

(b)

Figure 10: Rotor speed evolution for partial-load (a) and full-load (b) operation modes.

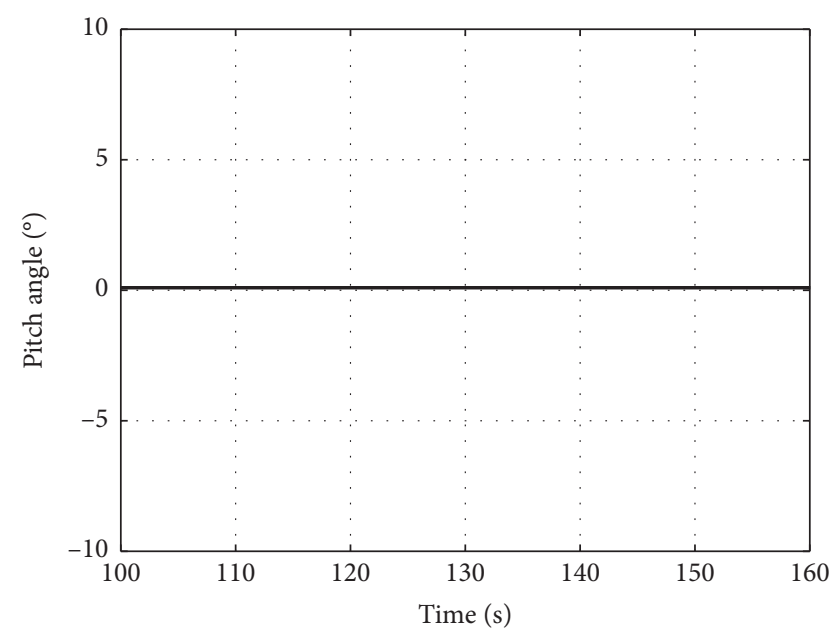

(a)

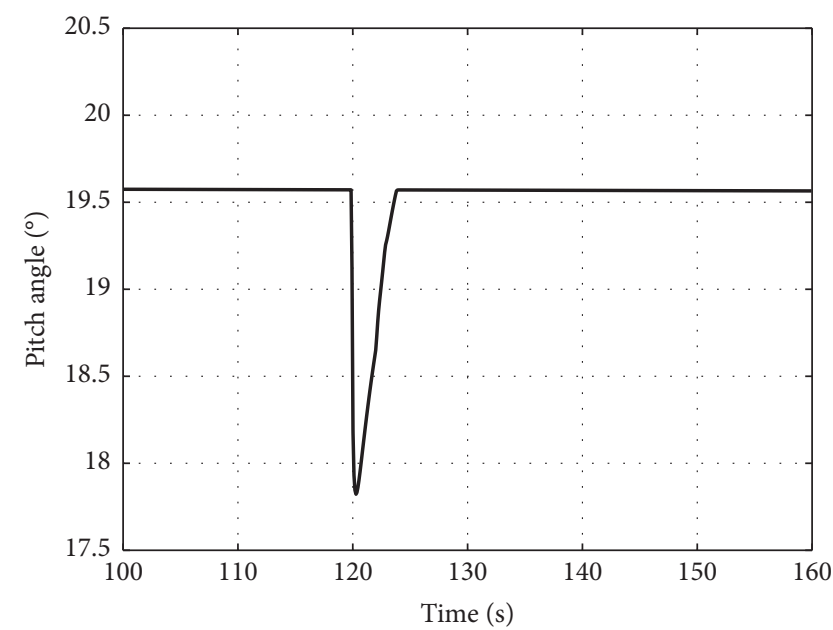

(b)

FIGURE 11: Pitch angle evolution for partial-load (a) and full-load (b) operation modes.

to recreate the power reserve (Figure 20(a)) for the next use

At the arrival of frequency excursion $(t=150 \mathrm{~s})$, the sequence of events that occur, under full-load operation mode, can be summarized as follows:

(i) The pitch control is now activated as shown in Figure 18(b), to keep the rotor speed at its maximum value (Figure 17(b)) and to create the power reserve (Figure 19(b)) since the rotor speed can no longer be accelerated

(ii) The active power call $\left(\Delta P_{\text {rsc }}\right.$, Figure 4$)$ reduced the pitch angle to make use of the mechanical power curtailed by the positive $\beta$

(iii) $\beta$ reduction increases the power coefficient $C_{P}$ as shown in Figure 19(b), consequently rising the output according to the amount of power specified by $\Delta P_{\text {rsc }}$ (Figure $20($ b))

(iv) When the frequency recovers at $t=400 \mathrm{~s}$, the pitch control strategy rises the pitch angle (Figure 18(b)), lowering the power coefficient (Figure 19(b)), in order to recreate the power reserve (Figure 20(b)) for the next use

4.5. Coordinated Control. The artificial inertial reaction, the speed droop control, and the pitch control could be used altogether, to further enhance the frequency regulation capability of WTs. In this subsection, we compared the simulation scenarios summarized in Table 2, with S1 being the reference case where the wind power penetration is $L_{p}=0 \%$. For the other simulation scenarios, the fourth generation synchronous is replaced with a WF with an 

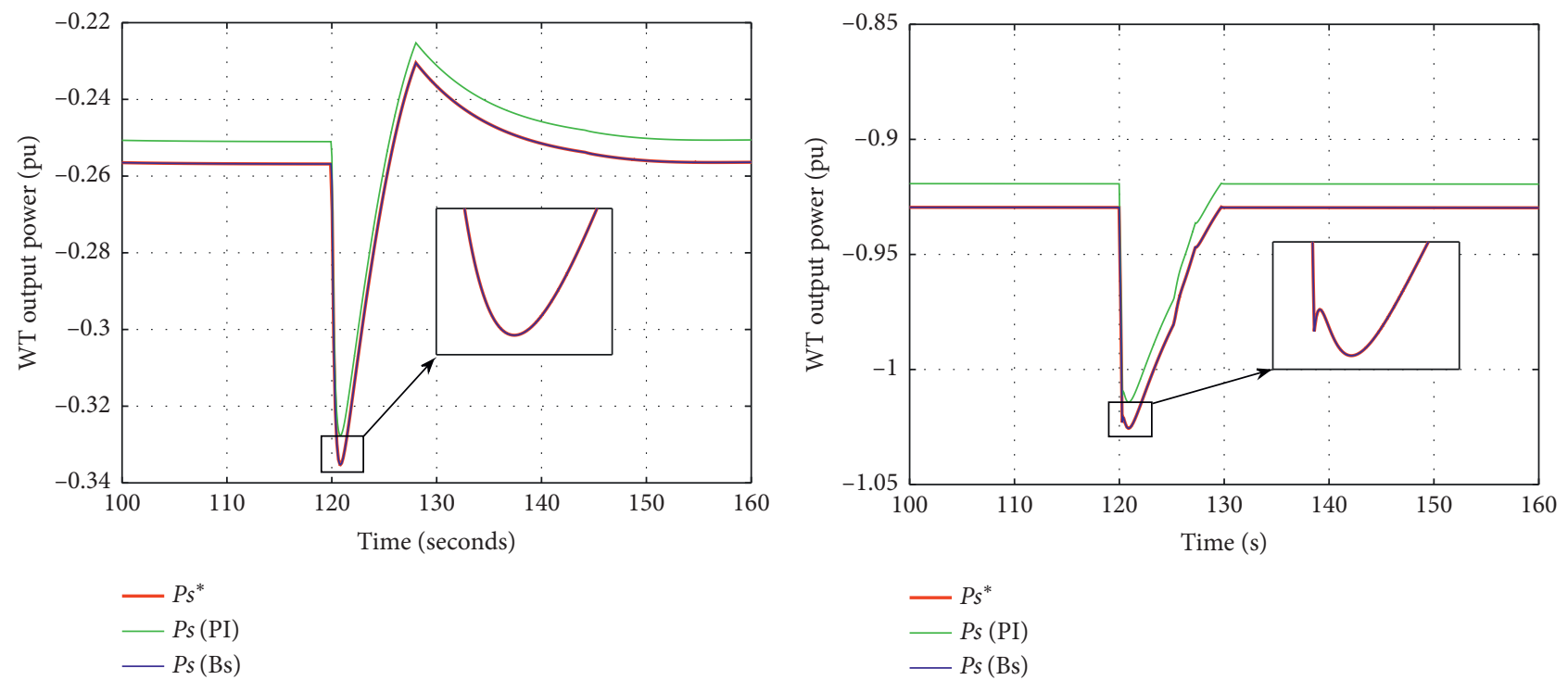

(a)

(b)

FIgURE 12: Active power evolution for partial-load (a) and full-load (b) operation modes.

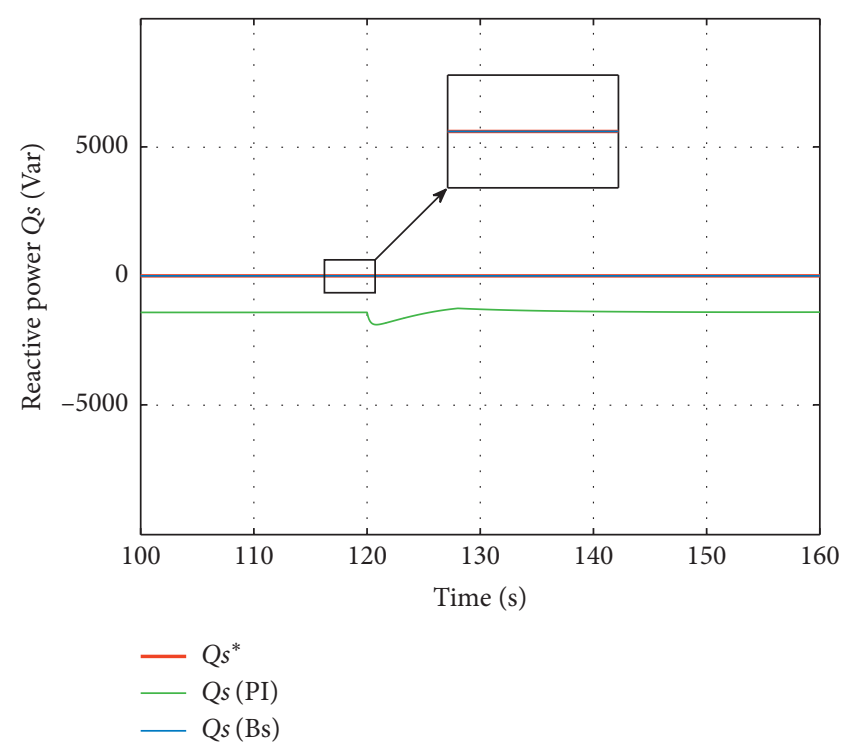

(a)

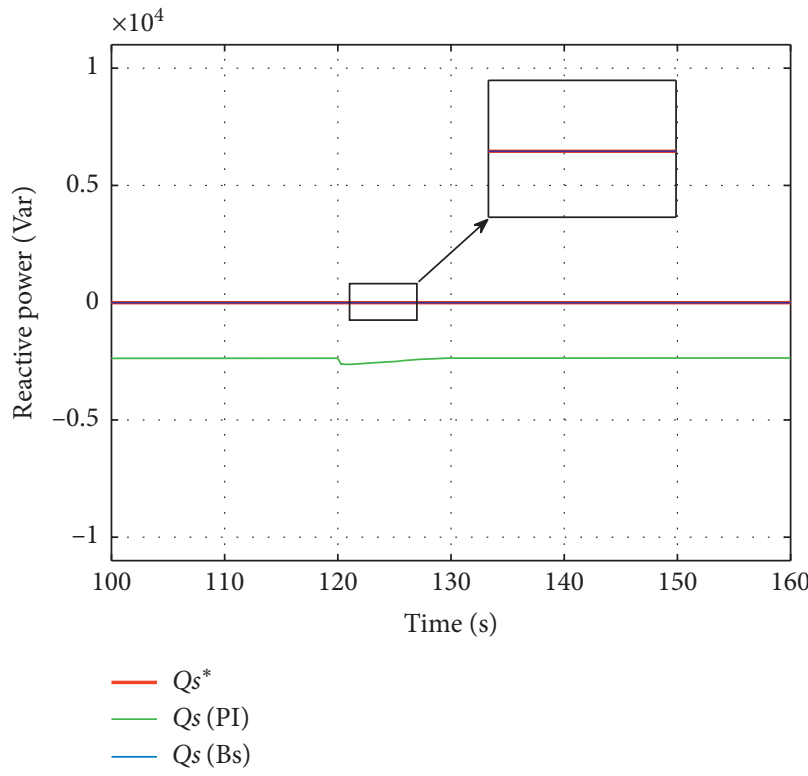

(b)

FIgURE 13: Reactive power evolution for partial-load (a) and full-load (b) operation modes.

equivalent power rating, and the wind power penetration rises to $L_{p}=25 \%$, with $S 2, S 3, S 3$, and S4 being, respectively, the cases without any frequency control, the inertial reaction only, speed droop control only, and all controllers.

Figure 21 portrays the dynamic reaction of the frequency for each scenario. All simulations were performed for a medium wind speed of $v_{w}=9 \mathrm{~m} / \mathrm{s}$, and a sudden rise in load by $0.05 \mathrm{pu}$ system base is introduced to the system at $t=200 \mathrm{~s}$.

The results show that the severest case is obtained with the simulation scenario $\mathrm{S} 2$, the case where the WF is connected with no frequency regulation ability. Compared to the reference case $\mathrm{S} 1$, where the wind power penetration $L_{p}=0 \%$, the frequency curve for the second simulation scenario S2 falls to a deeper nadir due to the reduction of the system's equivalent inertia caused by increasing the wind power penetration $L_{p}=25 \%$. On the other hand, in the case where the inertial control is implemented S3, the WT decelerates to release a portion of its kinetic energy transiently improving the frequency deviation. Consequently, the frequency nadir is lifted up to the level of the reference case S1. However, the quasi-steady-state frequency does not get any 

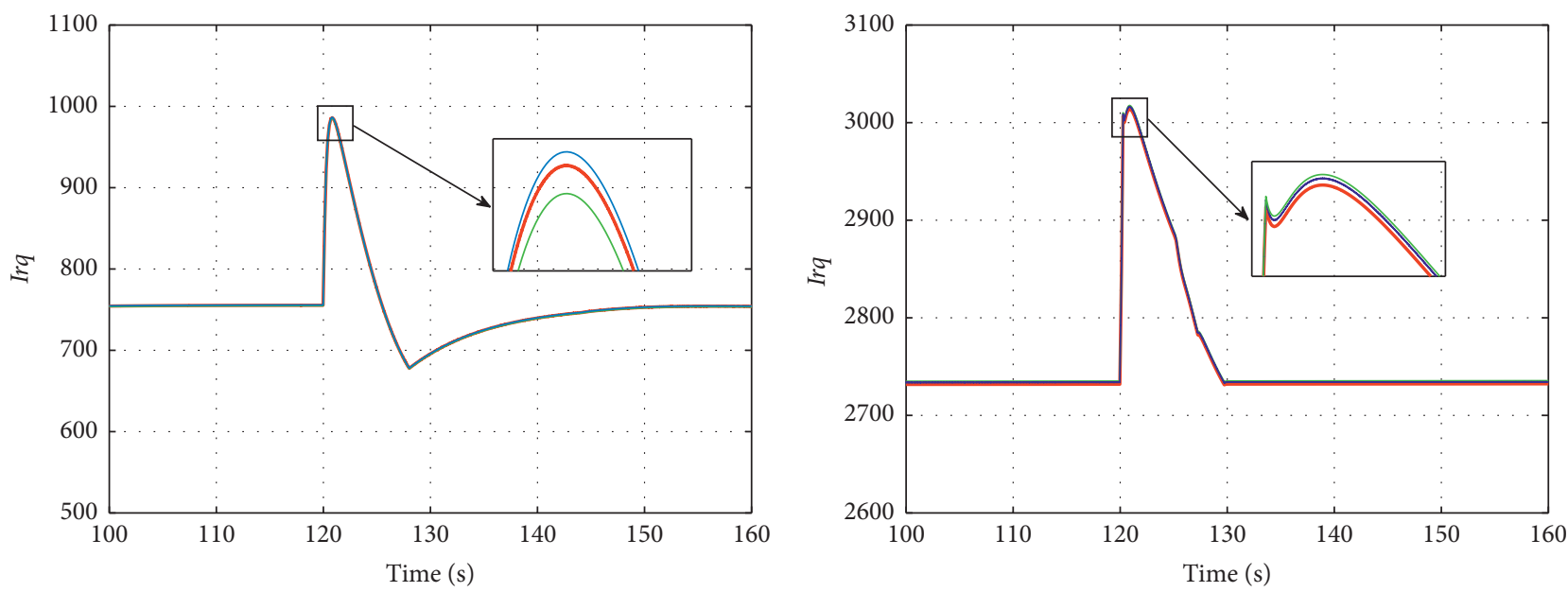

$$
\begin{aligned}
& -I_{r q}{ }^{*} \\
& -I_{r q}(\mathrm{PI}) \\
& -I_{r q}(\mathrm{Bs})
\end{aligned}
$$

$$
\begin{aligned}
& -I_{r q}{ }^{*} \\
& -I_{r q}(\mathrm{PI}) \\
& -I_{r q}(\mathrm{Bs})
\end{aligned}
$$

(a)

(b)

Figure 14: Active current $I_{r q}$ evolution for partial-load (a) and full-load (b) operation modes.

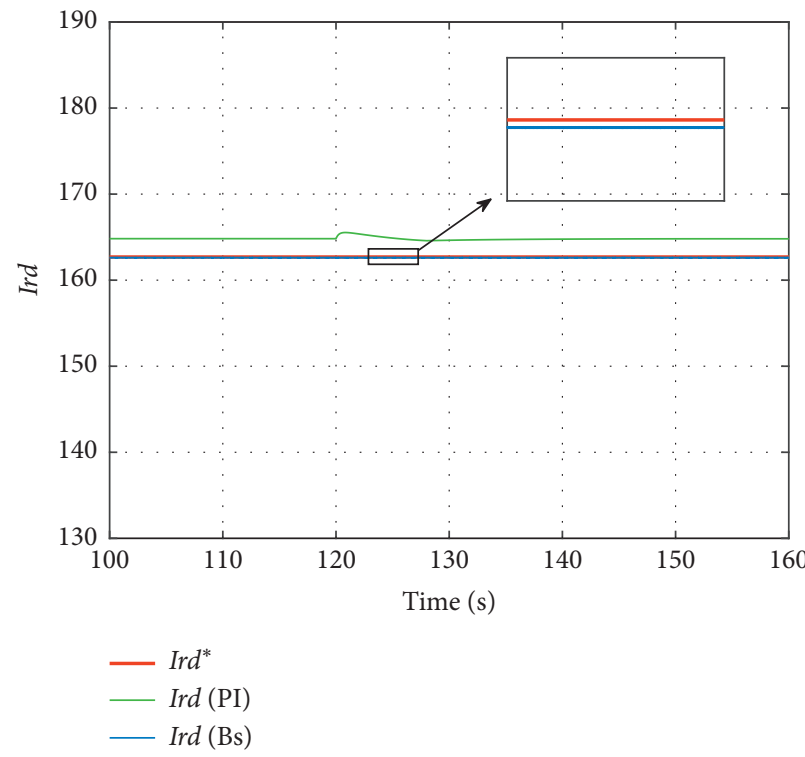

(a)

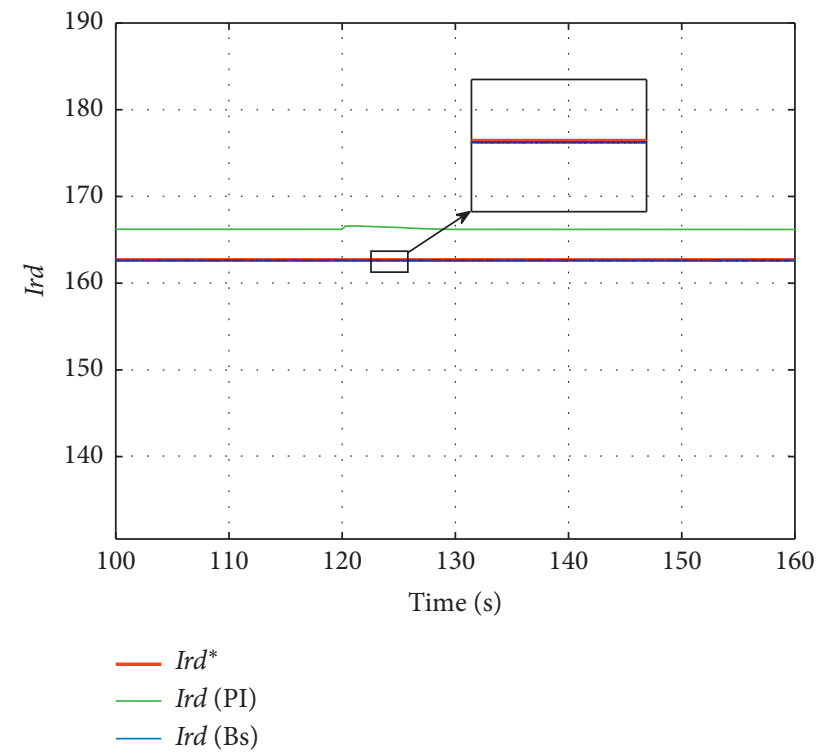

(b)

FIgURE 15: Reactive current $I_{r d}$ evolution for partial-load (a) and full-load (b) operation modes.

better with only the inertial control being enabled, since it provides only short-term frequency support. With the speed droop controller being enabled, simulation scenario S4, it can be observed that the WT contribution is higher since the maximum transient and the quasi-steady-state frequency deviations are both optimised. Finally, with both controllers being simultaneously enabled, simulation scenario S5, the frequency curve will further be improved for both short- and long-term durations.

As mentioned previously, with only the inertial control being activated, at the event of frequency excursion, the rotor speed deceleration will impose a suboptimal power extraction, and then less power will be delivered until the full recovery of the WT to its optimum speed (Figure 10(c)). This recovery phase that generally lasts tens of seconds could be avoided when both controllers are simultaneously activated, given that the droop speed controller forces the WT to operate at a higher rotational speed $\left(\Omega>\Omega_{\text {mppt }}\right)$, left side of the curve (Figure 4). Therefore, when the WT decelerates, the operating point will climb toward the optimum point, and as a result, there will be no need for the WT to recover at the end of the inertial response. 


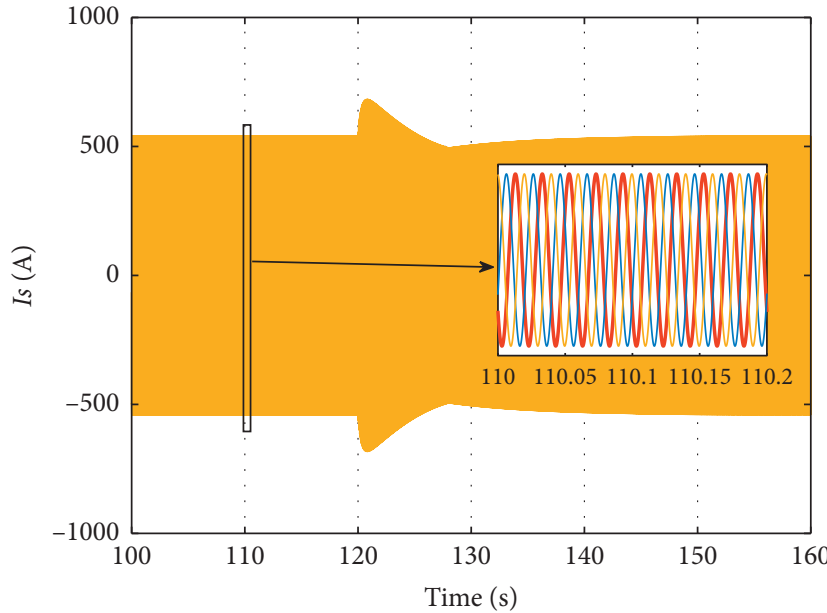

(a)

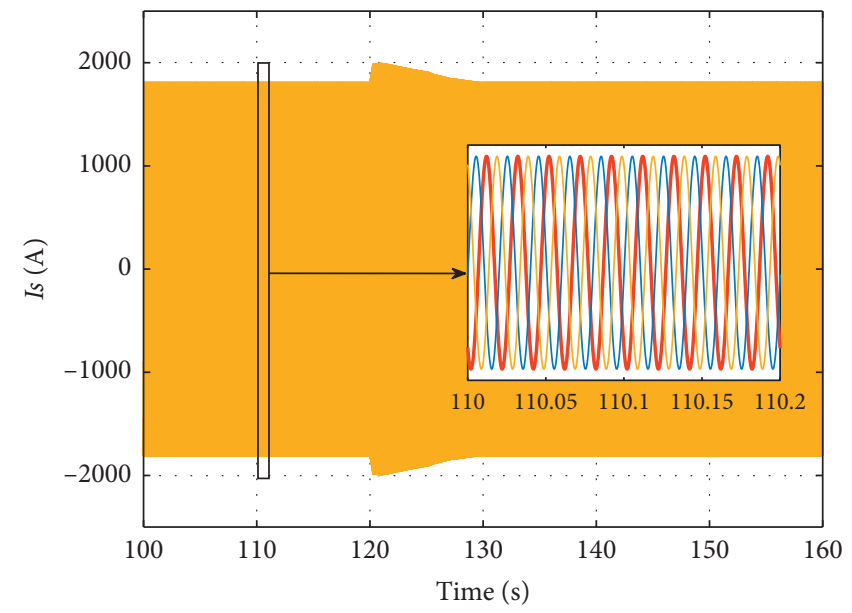

(b)

Figure 16: Stator current evolution for partial-load (a) and full-load (b) operation modes.

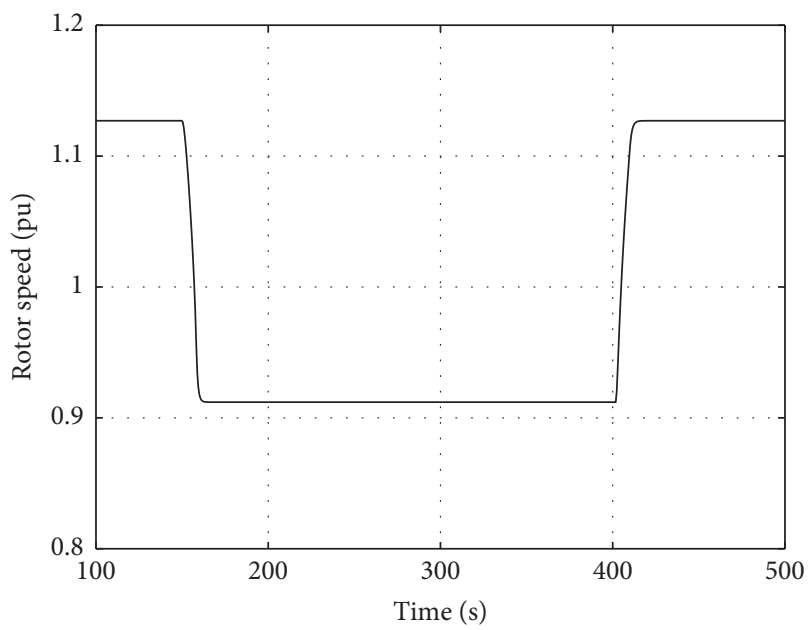

(a)

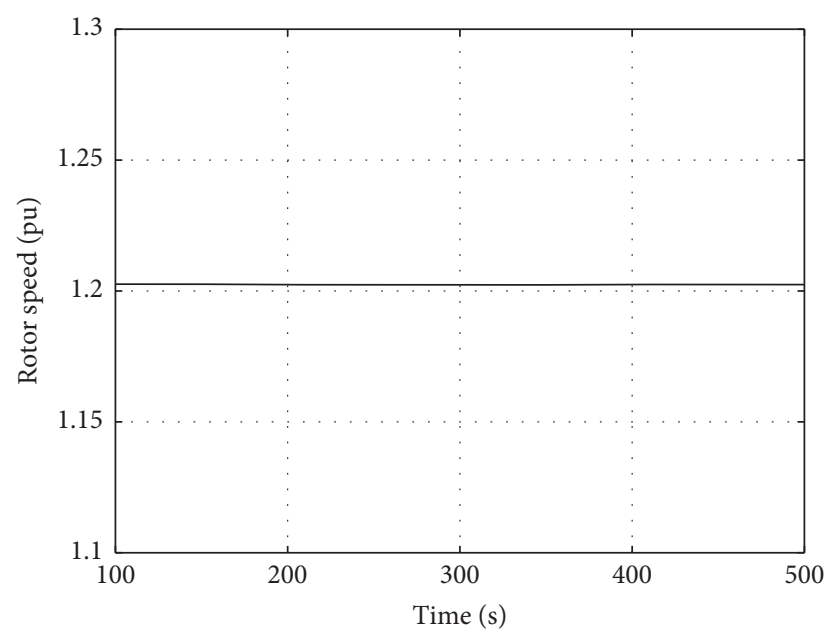

(b)

FIGURE 17: Rotor speed evolution for partial-load (a) and full-load (b) operation modes.

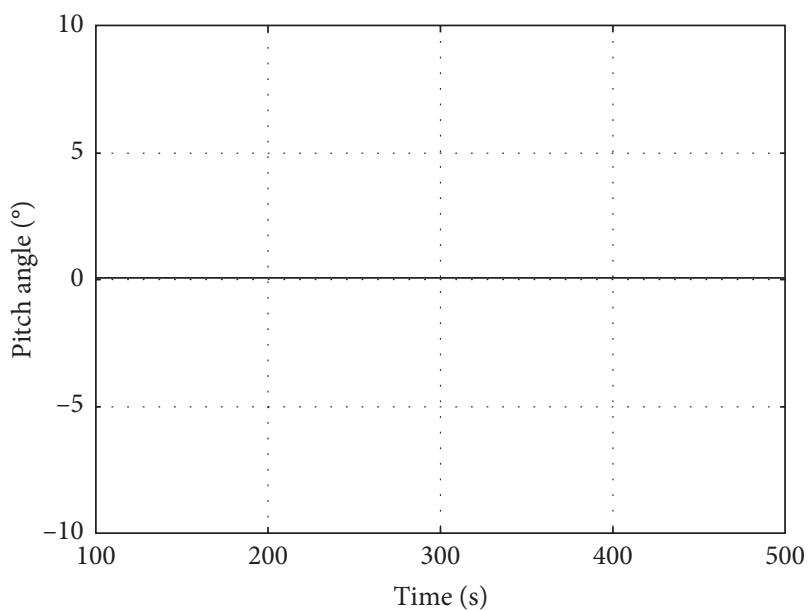

(a)

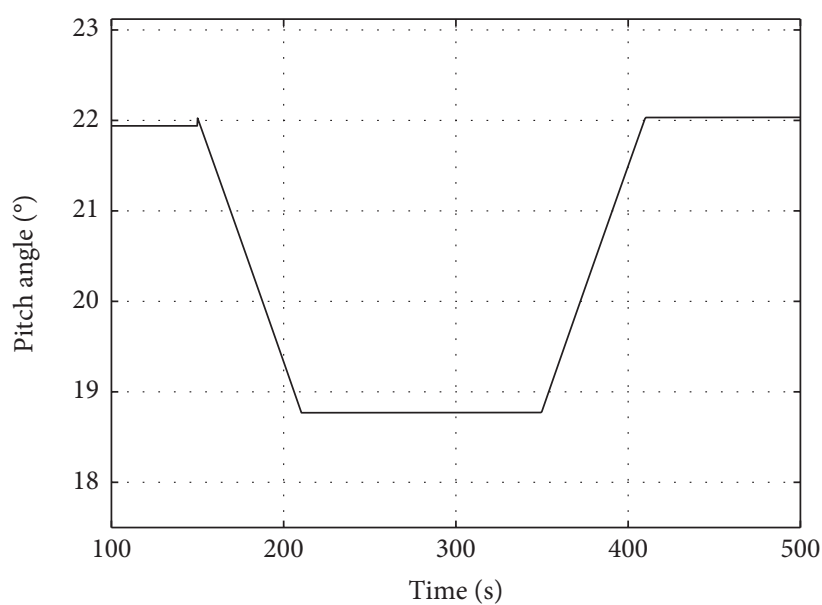

(b)

FIGURE 18: Pitch angle evolution for partial-load (a) and full-load (b) operation modes. 

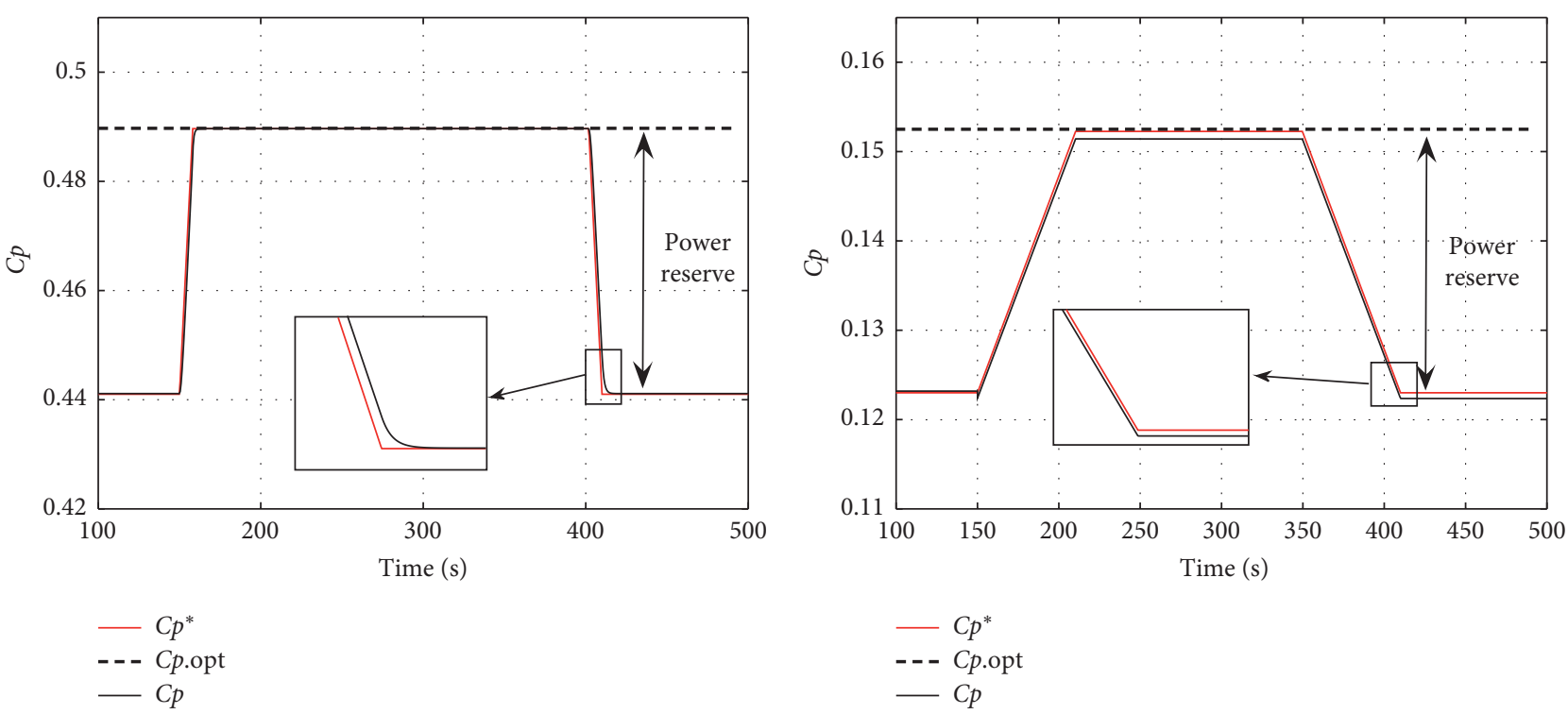

(a)

(b)

Figure 19: Power coefficient evolution for partial-load (a) and full-load (b) operation modes.

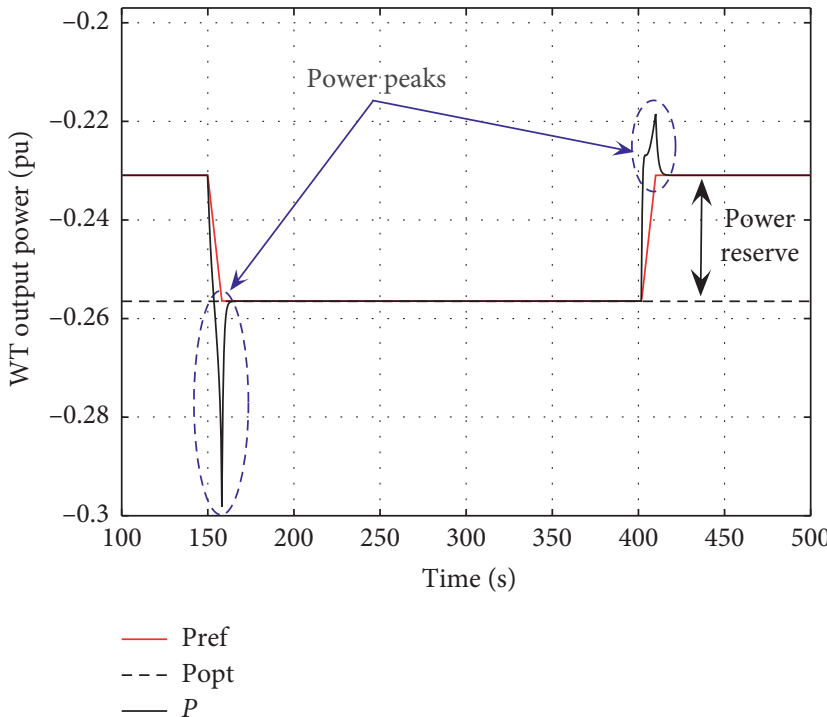

(a)

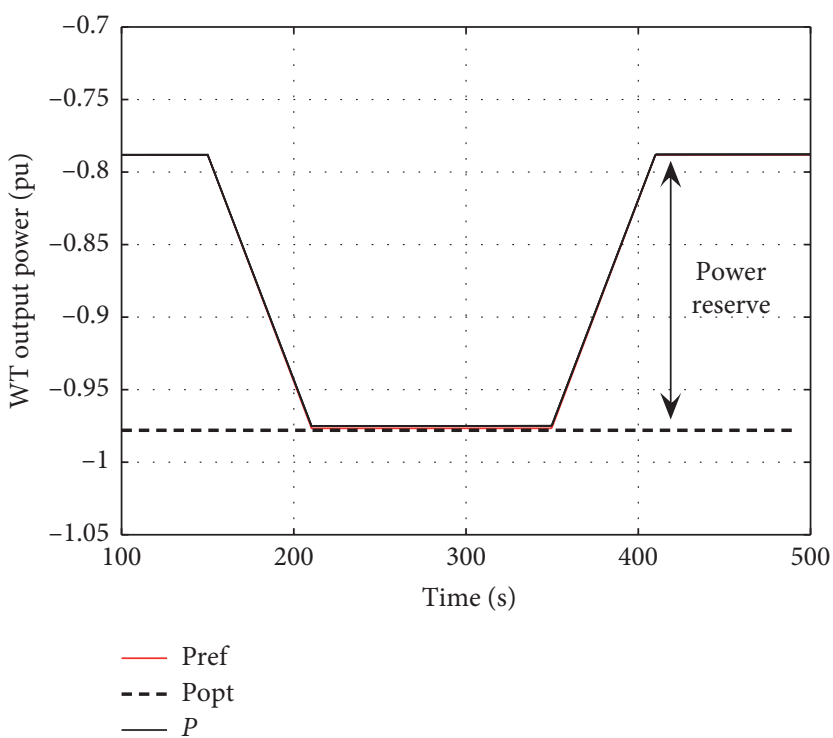

(b)

Figure 20: WR output power evolution for partial-load (a) and full-load (b) operation modes.

TABLE 2: Simulation scenarios.

\begin{tabular}{lccccc}
\hline Scenarios & S1 & S2 & S3 & S3 & S4 \\
\hline Generation units 1, 2, and 3 & C & C & C & C & C \\
Generation unit 4 & C & NC & NC & NC & NC \\
Wind farm & NC & C no control & C only IC & C only PFC & C IC and PFC \\
\hline
\end{tabular}

C: connected; NC: nonconnected; PFC: primary frequency control; IC: inertial control. 


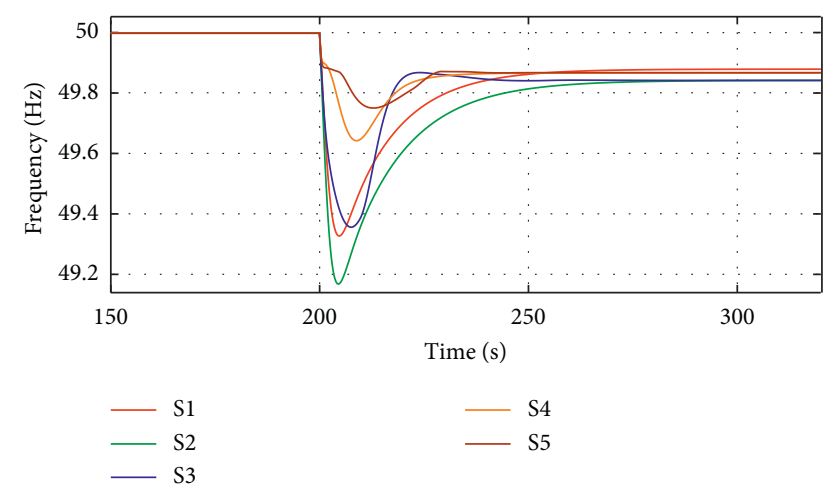

Figure 21: Deviation of the frequency for each simulation scenario.

\section{Conclusion}

This paper explores different control approaches that allow DFIG-based WTs to engage actively in frequency regulation, via coordinating the rotor speed and the pitch angle controllers. In a short-term duration, the inertial control permits the WT to emulate the synchronous generator natural behaviour. Accordingly, at the event of frequency excursion, the controller decelerates the WT in order to extract a portion of its kinetic energy, shortly providing extra active power support for the power system. However, the inertial reaction alone is heavily dependent on the initial point of operation and a good tuning of the controller gain is required since, for instance, at low wind speeds, the rotor speed should not exceed its minimum value $0.6 \mathrm{pu}$ for the stable operation of the WT. The speed droop controller enables the WT to provide active power assistance over an extended period improving the robustness of the system. It forces the WT to operate following a deloaded characteristic, creating a certain power reserve that can be automatically triggered at the event of frequency deviations. Moreover, an innovative pitch angle control is utilized to protect the WT against over speeding and to maintain the frequency regulation capability under various operation conditions.

Finally, a study case considering an isolated power system that consists of synchronous generators, DFIG-based wind farm, and static loads was examined to compare the performance of each controller. These simulation results show that the coordination of the controllers improves both the dynamic and the quasi-steady-state frequency deviation and brings the frequency nadir up to a far superior level than that obtained with the wind farm being disconnected $(0 \%$ wind power penetration).

\section{Appendix}

Wind turbine parameters

Rated power $P=2 \mathrm{MW}$, blade radius $R=45 \mathrm{~m}$, gearbox $G=90$. WT inertia $H_{\mathrm{WT}}=4.35 \mathrm{~s}$, damping coefficient $f=0.017 \mathrm{~N} \cdot \mathrm{m} \cdot \mathrm{s} / \mathrm{rd}$, and air density $\rho=1.2 \mathrm{~kg} / \mathrm{m}^{3}$.

DFIG parameters
Rated power $P=2 \mathrm{MW}$, rated torque $=12.7 \mathrm{kNm}$; grid rated voltage and frequency $V_{s}=690 \mathrm{~V}$ and $f_{s}=50 \mathrm{~Hz}$, pole pair $p=2$, generator inertia $H_{G}=0.5 \mathrm{~s}$, stator and rotor resistances $R_{s}=2.6 \mathrm{~m} \Omega$ and $R_{r}=2.9 \mathrm{~m} \Omega$, stator and rotor inductance $L_{s}=20 \mathrm{mH}$ and $L_{r}=20 \mathrm{mH}$, and mutual inductance $M=325.3 \mathrm{mH}$.

Power coefficient expression

$$
\begin{gathered}
C_{p}=X_{1}\left(\left(\frac{X_{2}}{\lambda+0.008 \beta}-\frac{0.0035 \cdot X_{2}}{\beta^{3}+1}\right)-X_{3} \beta-X_{4}\right) \\
\cdot \exp \left(\frac{X_{5}}{\lambda+0.008 \beta}-\frac{0.0035 \cdot X_{5}}{\beta^{3}+1}\right)+X_{6} \lambda
\end{gathered}
$$

$$
\begin{aligned}
& X_{1}=0.5109, \\
& X_{2}=116, \\
& X_{3}=0.4, \\
& A_{4}=5, \\
& X_{5}=21, \\
& X_{6}=0.0068 .
\end{aligned}
$$

\section{Data Availability}

No data were used to support this study.

\section{Disclosure}

This paper is an expanded version of a paper entitled "Inertial Response using Backstepping Control from DFIG based Wind Power Plant for Short-Term Frequency Regulation" presented at 2019 International Conference on Control, Decision and Information Technologies, held in Paris, France, from 23 to 26 April 2019.

\section{Conflicts of Interest}

The authors declare that there are no conflicts of interest regarding the publication of this paper.

\section{References}

[1] Y. Li, Z. Xu, J. Zhang, and K. P. Wong, "Variable gain control scheme of DFIG-based wind farm for over-frequency support," Renewable Energy, vol. 120, pp. 379-391, 2018.

[2] N. R. Ullah, T. Thiringer, and D. Karlsson, "Temporary primary frequency control support by variable speed wind turbines- potential and applications," IEEE Transactions on Power Systems, vol. 23, no. 2, pp. 601-612, 2008.

[3] A. Molina-Garcia, I. Munoz-Benavente, A. D. Hansen, and E. Gomez-Lazaro, "Demand-side contribution to primary frequency control with wind farm auxiliary control," IEEE 
Transactions on Power Systems, vol. 29, no. 5, pp. 2391-2399, 2014.

[4] F. Poitiers, T. Bouaouiche, and M. Machmoum, "Advanced control of a doubly-fed induction generator for wind energy conversion," Electric Power Systems Research, vol. 79, no. 7, pp. 1085-1096, 2009.

[5] Z.-S. Zhang, Y.-Z. Sun, J. Lin, and G.-J. Li, "Coordinated frequency regulation by doubly fed induction generator-based wind power plants," IET Renewable Power Generation, vol. 6, no. 1, pp. 38-47, 2012.

[6] R. Chakib, M. Cherkaoui, and A. Essadki, "Inertial response used for a short term frequency control for DFIG wind turbine controlled by ADRC," ARPN: Journal of Engineering and Applied Sciences, vol. 11, no. 5, 2016.

[7] Y.-K. Wu, S.-M. Chang, and P. Mandal, "Grid-connected wind power plants: a survey on the integration requirements in modern grid codes," in Proceedings of the 2019 IEEE/IAS 55th Industrial and Commercial Power Systems Technical Conference (IঊCPS), pp. 1-9, Canada, Canada, May 2019.

[8] L. Ruttledge and D. Flynn, "Emulated inertial response from wind turbines: gain scheduling and resource coordination," IEEE Transactions on Power Systems, vol. 31, no. 5, pp. 3747-3755, 2015.

[9] A. I. Estanqueiro, J. M. F. De Jesus, J. Ricardo, A. dos Santos, and J. A. P. Lopes, "Barriers (and solutions...) to Very High Wind Penetration in Power Systems," in Proceedings of the 2007 IEEE Power Engineering Society General Meeting, pp. 1-7, Tampa, FL, USA, June 2007.

[10] Y. Wang, G. Delille, H. Bayem, X. Guillaud, and B. Francois, "High wind power penetration in isolated power systemsassessment of wind inertial and primary frequency responses," IEEE Transactions on Power Systems, vol. 28, no. 3, pp. 2412-2420, 2013.

[11] P.-K. Keung, P. Li, H. Banakar, and B. T. Ooi, "Kinetic energy of wind-turbine generators for system frequency support," IEEE Transactions on Power Systems, vol. 24, no. 1, pp. 279287, 2008

[12] H. Ye, W. Pei, and Z. Qi, "Analytical modeling of inertial and droop responses from a wind farm for short-term frequency regulation in power systems," IEEE Transactions on Power Systems, vol. 31, no. 5, pp. 3414-3423, 2015.

[13] H. Liu and Z. Chen, "Contribution of VSC-HVDC to frequency regulation of power systems with offshore wind generation," IEEE Transactions on Energy Conversion, vol. 30, no. 3, pp. 918-926, 2015.

[14] R. M. Kamel, A. Chaouachi, and K. Nagasaka, "Three control strategies to improve the microgrid transient dynamic response during isolated mode: a comparative study," IEEE Transactions on Industrial Electronics, vol. 60, no. 4, pp. 1314-1322, 2012.

[15] S. Wang, J. Hu, X. Yuan, and L. Sun, "On inertial dynamics of virtual-synchronous-controlled DFIG-based wind turbines," IEEE Transactions on Energy Conversion, vol. 30, no. 4, pp. 1691-1702, 2015.

[16] H. T. Ma and B. H. Chowdhury, "Working towards frequency regulation with wind plants: combined control approaches," IET Renewable Power Generation, vol. 4, no. 4, pp. 308-316, 2010.

[17] I. A. Gowaid, A. El-Zawawi, and M. El-Gammal, "Improved inertia and frequency support from grid-connected DFIG wind farms," in Proceedings of the Power Systems Conference and Exposition (PSCE), pp. 1-9, Phoenix, AZ, USA, March 2011.
[18] M. Nadour, A. Essadki, and T. Nasser, "Comparative analysis between PI \& backstepping control strategies of DFIG driven by wind turbine," International Journal of Renewable Energy Research, vol. 7, no. 3, pp. 1307-1316, 2017.

[19] M. Nadour, A. Essadki, M. Fdaili, and T. Nasser, "Advanced backstepping control of a wind energy conversion system using a doubly-fed induction generator," in Proceedings of the 2017 International Renewable and Sustainable Energy Conference (IRSEC), pp. 1-6, Tangier, Morocco, December 2017.

[20] Y. Rebours, A Comprehensive Assessment of Markets for Frequency and Voltage Control Ancillary Services, PhD thesis, University of Manchester, Manchester, England, 2008.

[21] P. Venne, X. Guillaud, R. Teodorescu, and J. Mahseredjian, "Generalized gain scheduling for deloaded wind turbine operation," Wind Engineering, vol. 34, no. 2, pp. 219-239, 2010.

[22] P. Kundur, N. J. Balu, and M. G. Lauby, Power System Stability and Control, Vol. 7, McGraw-Hill, New York, NY, USA, 1994.

[23] J. Van de Vyver, J. D. M. De Kooning, B. Meersman, L. Vandevelde, and T. L. Vandoorn, "Droop control as an alternative inertial response strategy for the synthetic inertia on wind turbines," IEEE Transactions on Power Systems, vol. 31, no. 2, pp. 1129-1138, 2016. 